\title{
Anterior Cingulate Synapses in Prefrontal Areas 10 and 46 Suggest Differential Influence in Cognitive Control
}

\author{
Maria Medalla ${ }^{1}$ and Helen Barbas ${ }^{1,2}$ \\ ${ }^{1}$ Department of Health Sciences, and 2 Program in Neuroscience, Boston University and School of Medicine, Boston, Massachusetts 02215
}

\begin{abstract}
Dorsolateral prefrontal areas 46 and 10 are involved in distinct aspects of cognition. Area 46 has a key role in working memory tasks, and frontopolar area 10 is recruited in complex multitask operations. Both areas are innervated by the anterior cingulate cortex (ACC), a region associated with emotions and memory but is also important for attentional control through unknown synaptic mechanisms. Here, we found that in rhesus monkeys (Macaca mulatta) most axon terminals labeled from tracers injected into ACC area 32 innervated spines of presumed excitatory neurons, but $\sim 20-30 \%$ formed mostly large synapses with dendritic shafts of presumed inhibitory neurons in the upper layers (I-IIIa) of dorsolateral areas 10, 46, and 9. Moreover, area 32 terminals targeted preferentially calbindin and, to a lesser extent, calretinin neurons, which are thought to be inhibitory neurons that modulate the gain of task-relevant activity during working memory tasks. Area 46 was distinguished as a recipient of more (by $\sim 40 \%$ ) area 32 synapses on putative inhibitory neurons. Area 10 stood apart as recipient of significantly larger (by $\sim 40 \%$ in volume) area 32 terminals on spines of putative excitatory neurons. These synaptic specializations suggest that area 32 has complementary roles, potentially enhancing inhibition in area 46 and strengthening excitation in area 10, which may help direct attention to new tasks while temporarily holding in memory another task.
\end{abstract}

\section{Introduction}

Our thoughts are constantly bombarded by a multitude of stimuli, yet we can keep track of sequences in tasks and juggle multiple operations, though not always successfully. These functions, which broadly engage working memory mechanisms, are mediated by distinct dorsolateral prefrontal areas. In particular, areas 46 and 9 are involved in classic working memory functions, and their damage severely impairs the ability to keep track of information for the task at hand (for review, see Levy and GoldmanRakic, 2000; Petrides, 2005). Neurons in dorsolateral prefrontal areas have sustained activity during the delay period of delayedresponse tasks, which is thought to be a physiologic correlate of working memory (Fuster, 1973; Niki and Watanabe, 1976) (for review, see Goldman-Rakic, 1995; Fuster, 2001; Constantinidis and Procyk, 2004; Funahashi, 2006). However, when one task must be temporarily suspended to attend to another task, frontopolar area 10 is also recruited (for review, see Smith et al., 2007; Burgess et al., 2007; Koechlin and Hyafil, 2007; Badre and D'Esposito, 2009). The mechanism that underlies the functional dissociation of area 10 from other dorsolateral prefrontal areas in cognitive processing is unknown.

\footnotetext{
Received April 5, 2010; revised Sept. 17, 2010; accepted Sept. 20, 2010.

This work was supported by National Institutes of Health grants from National Institute of Neurological Disorders and Stroke and National Institute of Mental Health; and in part by the Center of Excellence for Learning in Education, Science, and Technology, a National Science Foundation (NSF) Science of Learning Center (NSF Grant SBE-0354378). We thank Marcia Feinberg and Sue Paul for technical assistance; Kiran Bhai, Brittany Bolton, and Stephanie Jackson for help with data analysis; Dr. John Fiala for help with three-dimensional reconstruction; Dr. Alan Peters, Dr. Jennifer Luebke, and Dr, Michael Hasselmo for helpful comments; and Dr. Ron Killiany for help with surgery and imaging.

Correspondence should be addressed to Helen Barbas, Department of Health Sciences, Boston University, 635 Commonwealth Avenue, Room 431, Boston, MA 02215. E-mail: barbas@bu.edu.

DOI:10.1523/JNEUROSCI.1773-10.2010

Copyright $\odot 2010$ the authors $\quad$ 0270-6474/10/3016068-14\$15.00/0
}

An equally important region in cognitive control is the anterior cingulate cortex (ACC), which interacts robustly with dorsolateral prefrontal areas (Barbas et al., 1999) but is functionally distinct (for review, see Devinsky et al., 1995; Carter et al., 1999; Bush et al., 2000; Paus, 2001; Matsumoto and Tanaka, 2004; Rushworth et al., 2007). Unlike dorsolateral areas, the ACC has strong bidirectional connections with limbic structures involved in emotions and long-term memory. The ACC is engaged during demanding cognitive tasks and is thought to have a key role in cognitive-emotional interactions (for review, see Barbas, 1995; Barbas and Zikopoulos, 2007; Botvinick, 2007; Lee et al., 2007; Schall and Boucher, 2007; Pessoa, 2008). Previously, we have shown that when axons from ACC area 32 form synapses with putative inhibitory neurons in the upper layers (I-IIIa) of dorsolateral area 9 the boutons are larger than terminals from the functionally related dorsolateral area 46 (Medalla and Barbas, 2009). Large boutons have more synaptic vesicles, a feature correlated with a higher probability of neurotransmitter release with each action potential (Tong and Jahr, 1994; Murthy et al., 1997, 2001). Thus, the synaptic interaction of these pathways suggests that, compared with area 46 , area 32 can potentially engage more effectively inhibition in area 9 and help suppress noise and reverse decisions during demanding cognitive tasks (Medalla and Barbas, 2009).

Here, we investigated whether ACC area 32 of rhesus monkeys has a similar or different synaptic interaction with putative excitatory and inhibitory neurons in other dorsolateral prefrontal areas. Specifically, we focused on synapses formed by area 32 with neuronal elements in the functionally distinct dorsolateral area 46 and the dorsolateral part of frontopolar area 10. We provide evidence of synaptic specificity in the pathways from area 32 to areas 46 and 10, in circuits that support their specialization in distinct aspects of working memory and cognitive control. 


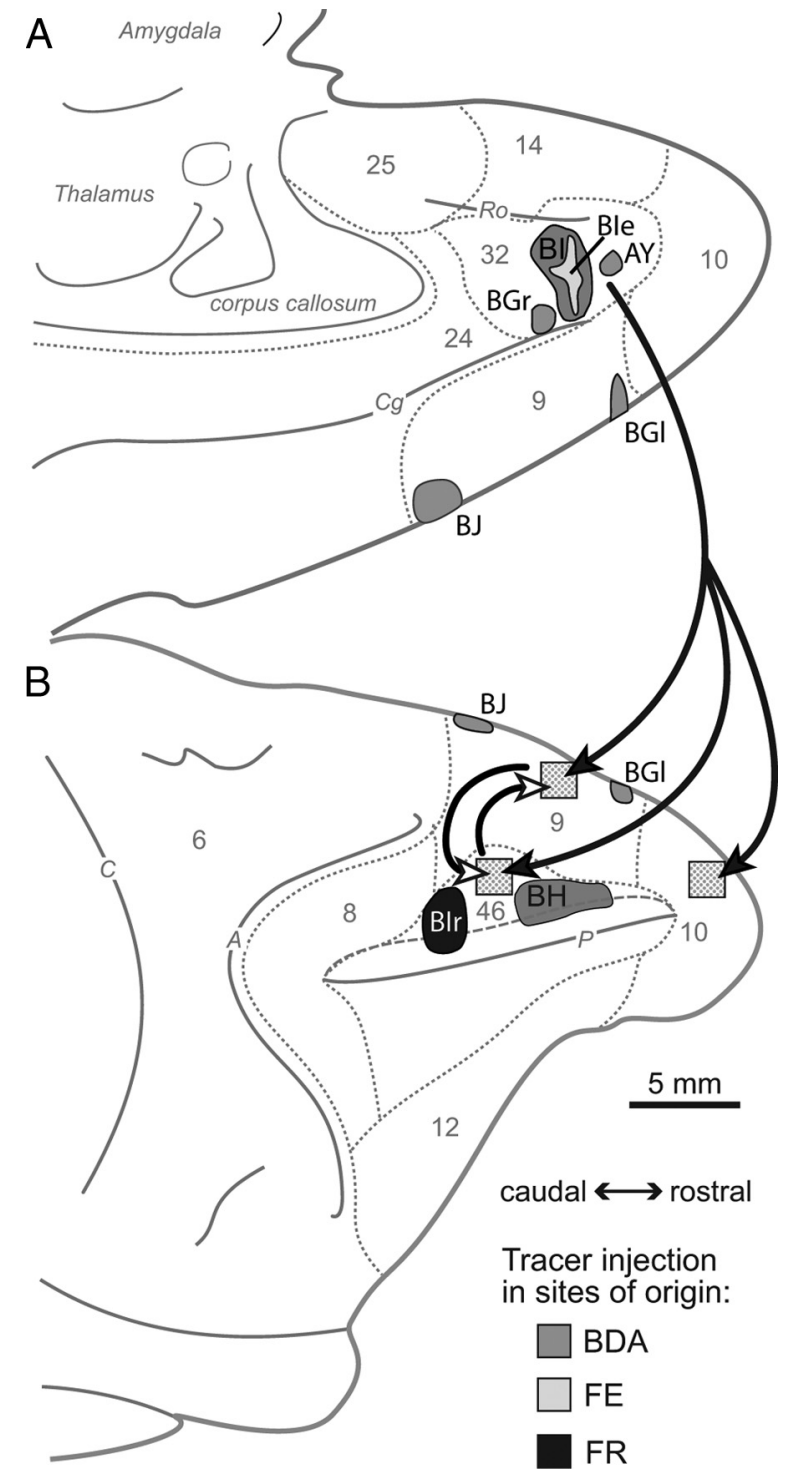

Figure 1. Tracing anterior cingulate and dorsolateral prefrontal pathways. A, Sites of injection of distinct neural tracers in the $\mathrm{ACC}$ (area 32; cases AY, BGr, BI, and Ble) are shown on the medial surface of the rhesus monkey brain. $\boldsymbol{B}$, Lateral surface shows the location of sites examined in areas 10,46, and 9 (dotted-filled squares) for labeled axonal boutons from area 32 (black arrowheads). For comparison, pathways connecting the related dorsolateral areas 46 and 9 (silhouette arrowheads) were labeled by placing distinct tracer injections in dorsal area 46 (cases Blr and BH; extending into the dorsal bank of the principal sulcus demarcated by long dashes) and the dorsal part of area 9 (cases BJ and BGl; extending from the lateral surface to the dorsomedial surface in $\boldsymbol{A}$ ). Short dashed lines mark areal boundaries. A, Arcuate sulcus; $C$, central sulcus; $C g$, cingulate sulcus; $P$, principal sulcus; Ro, rostral sulcus.

\section{Materials and Methods}

\section{Surgical procedures and injection of neural tracers}

Tracer injections were made in normal rhesus monkeys (Macaca mulatta; $2-3$ years of age; $n=5$ ), using magnetic resonance imaging (MRI), surgical, and tissue-processing protocols described previously (Medalla et al., 2007; Medalla and Barbas, 2009). Animals were obtained from the New England Primate Research Center (NEPRC), and protocols were approved by the Institutional Animal Care and Use Committee at NEPRC, Harvard Medical School, and Boston University in accordance with National Institutes of Health (NIH) guidelines (Department of Health, Education, and Welfare Publication No. NIH 80-22, revised 1987, Office of Science and Health Reports, Division of Receipt and Referral/NIH, Bethesda, MD).

Figure 1 summarizes the overall experimental design and distinct injection sites in ACC area 32 and dorsolateral prefrontal areas 46 and 9.
Injection sites were based on stereotaxic coordinates calculated from MRI scans obtained before surgery, as described previously (Zikopoulos and Barbas, 2007). To calculate coordinates for the injection sites, we used as reference points for the dorsoventral dimension the pial surface, for the mediolateral dimension the midline, and for the rostrocaudal dimension the ear bar tips, which had been filled with a marker (betadine) that is visible in the MRI.

About a week after the MRI, surgery was performed under aseptic conditions while heart rate, muscle tone, respiration, and pupillary dilatation were closely monitored. The monkeys were anesthetized with ketamine hydrochloride $(10-15 \mathrm{mg} / \mathrm{kg}$, i.m.) followed by isoflurane anesthetic until a surgical level of anesthesia was accomplished. The monkeys were then placed in a stereotaxic apparatus and a small region of the prefrontal cortex was exposed over the injection site. Using a microsyringe ( 5 or $10 \mu \mathrm{l}$ syringes, Hamilton) mounted on a microdrive, we injected the bidirectional neural tracers biotinylated dextran amine (BDA, Invitrogen) (cases AY, BGl, BGr, BH, BI, and BJ), fluoroemerald (FE, dextran fluorescein, Invitrogen) (case BIe), or fluororuby (FR, dextran tetramethylrhodamine, Invitrogen) (case BIr). All tracers were dextran amines of $10 \mathrm{kDA}$ molecular weight, optimized for anterograde labeling, as described (Veenman et al., 1992; Reiner et al., 2000) (our personal observations). These dextran amines label the entire extent of axonal fibers and boutons. They also label neurons retrogradely, but labeling is sporadic and restricted to the cell bodies and proximal dendrites of projection neurons and does not appear to enter axon collaterals (Veenman et al., 1992; Reiner et al., 2000). For each injection site, the dye was diluted to $10 \mathrm{mg} / \mathrm{ml}$ in distilled water and delivered in two to four penetrations spaced $0.5 \mathrm{~mm}$ apart, to inject a total volume of $\sim 5 \mu$ l of dye.

\section{Perfusion and tissue processing}

After a survival period of $18 \mathrm{~d}$, the animals were given an overdose of anesthetic (sodium pentobarbital, $>50 \mathrm{mg} / \mathrm{kg}$ ) until a deep level of anesthesia was achieved, then transcardially perfused with freshly depolymerized $4 \%$ paraformaldehyde and $0.2 \%$ glutaraldehyde (EM grade; Ladd Research Industries) in $0.1 \mathrm{M}$ phosphate buffer (PB; with $9 \% \mathrm{NaCl}$, $\mathrm{pH}$ 7.4). The fixative solution was warmed to body temperature $\left(37^{\circ} \mathrm{C}\right)$ at the time of perfusion. The brains were then removed from the skull, cryoprotected in graded solutions of sucrose $(10-30 \%)$, frozen in $-70^{\circ} \mathrm{C}$ isopentane (Rosene et al., 1986), and cut on a freezing microtome in the coronal plane at $50 \mu \mathrm{m}$ to produce 10 series per hemisphere. To preserve the ultrastructure, tissue was stored until use at $-20^{\circ} \mathrm{C}$ in antifreeze solution (30\% ethylene glycol, $30 \%$ glycerol, $40 \% 0.05$ м PB, pH 7.4, with $0.05 \%$ azide).

Immunohistochemistry for bright-field microscopy. To visualize the neural tracers $\mathrm{BDA}, \mathrm{FE}$, and FR using bright-field microscopy, we used the avidin-biotin $(\mathrm{AB})$ with horseradish peroxidase (HRP) method (Vectastain PK-6100 ABC Elite kit, Vector Laboratories), as described previously (Medalla et al., 2007; Medalla and Barbas, 2009). Assays were conducted on free-floating sections $\left(\right.$ at $\left.4^{\circ} \mathrm{C}\right)$. Tissue sections were first incubated in $0.05 \mathrm{~m}$ glycine and preblocked in 5\% normal goat serum (NGS) and $5 \%$ bovine serum albumin (BSA) with $0.2 \%$ Triton-X. Sections with BDA label were incubated in AB-HRP solution for $1 \mathrm{~h}(1: 100$ in $\mathrm{PBS}$ with $0.1 \%$ Triton $\mathrm{X}$ ), and then processed using the peroxidasecatalyzed polymerization of diaminobenzidine (DAB) for 2-3 $\min (\mathrm{DAB}$ kit, Vector Laboratories or Zymed Laboratories). Sections with fluorescent tracers were incubated overnight in antibodies against FE or FR (1:800 in PBS, $1 \%$ NGS, $1 \%$ BSA, $0.1 \%$ Triton-X; rabbit polyclonal, Invitrogen), followed by incubations in secondary biotinylated goat anti-rabbit IgG (1:200, for $2 \mathrm{~h}$; Vector Laboratories), then in AB-HRP and $\mathrm{DAB}$, as described above. For FE and FR cases, where there was also an injection of BDA in the same animal, sections were incubated in avidin-biotin blocking reagent (AB blocking kit, Vector Laboratories) before immunobinding, to prevent cross-reaction with BDA, as described previously (Medalla et al., 2007). After processing, sections were mounted on gelatin-coated slides, dehydrated in alcohol, and coverslipped with Entellan (EMD Chemicals). To delineate areas and layers, every other section in a series was counterstained with thionin (Sigma). 
Pre-embedding immunohistochemistry for electron microscopy. We used pre-embedding immunohistochemistry to view synapses of labeled pathways in the electron microscope (EM; 100CX JEOL), as described previously (Medalla et al., 2007; Medalla and Barbas, 2009). We labeled neurons for the expression of the calcium-binding proteins parvalbumin $(\mathrm{PV})$, calretinin (CR), and calbindin (CB), which label distinct and nonoverlapping neurochemical classes of inhibitory neurons in the cortex in primates (for review, see DeFelipe, 1997). We used triple immunohistochemical methods to label neural tracers with DAB (as described above), and PV, CR, or CB neurons either with silver-enhanced, goldconjugated secondary antibodies or tetramethylbenzidine (TMB), as described previously (Medalla et al., 2007). The three methods show distinct labeling at the EM: DAB appears as a dark uniform precipitate, silver-enhanced gold particles as circular clumps of variable size, and TMB as rod-shaped crystals (Gonchar and Burkhalter, 2003; Pinto et al., 2003; Moore et al., 2004; Medalla et al., 2007; Zikopoulos and Barbas, 2007) (our personal observations).

After labeling fibers with DAB (as above, except for reduced amounts of Triton-X, $0.025 \%$ ), sections were incubated in $\mathrm{AB}$ blocking reagent to prevent cross-reaction with TMB. For BDA-labeled tissue, sections were coincubated overnight in the primary antibodies for PV or CR (1:2000, rabbit polyclonal) and CB (1:2000, mouse monoclonal; Swiss Antibodies), and then in biotinylated anti-mouse IgG, followed by AB-HRP. For FE- or FR-labeled tissue, we used a combination of two mouse monoclonal primary antibodies for $\mathrm{PV}, \mathrm{CB}$, or $\mathrm{CR}$, processed successively, using the Mouse-on-Mouse blocking kit (M.O.M. basic kit; Vector Laboratories) in between to prevent cross-reaction. Sections were incubated overnight in the appropriate gold-conjugated IgG (1:50, $1 \mathrm{~nm}$ gold particle diameter; GE Healthcare). Sections were then postfixed in $6 \%$ glutaraldehyde with $2 \%$ paraformaldehyde using a variable wattage microwave (for 3-6 min at $150 \mathrm{~W}$ in the Biowave; Ted Pella) until the fixative temperature reached $30^{\circ} \mathrm{C}$. Gold labeling was intensified with silver (6-12 min; IntenSE M kit; GE Healthcare), which results in aggregates of gold particles of variable sizes. Sections were processed for TMB then stabilized with DAB-cobalt chloride solution, as described previously (Medalla et al., 2007). In control experiments, we omitted primary antibodies to test the specificity of secondary antibodies, and used the $\mathrm{AB}$ blocking kit before $\mathrm{AB}$ binding, and the M.O.M. kit before secondary antibody binding. In all control experiments, there was no immunohistochemical labeling.

After immunohistochemical procedures, we cut small pieces of cortex (all layers) with anterograde label in areas 10, 46, and 9. The tissue pieces were postfixed in osmium, rinsed, dehydrated in increasing concentrations of ethanol $(50-100 \%)$, stained with $1 \%$ uranyl acetate (EM Science), infiltrated with propylene oxide, and flat embedded in Araldite (Fullam) or LX112 resin (Ladd Research Industries) using Aclar plastic (Ted Pella), as described previously (Medalla et al., 2007; Medalla and Barbas, 2009). Pieces of Aclar-embedded tissue were cut and reembedded in resin blocks, and sectioned at $50 \mathrm{~nm}$ with a diamond knife (Diatome US) using an ultramicrotome (Ultracut; Leica), as elaborated below. Serial ultrathin sections were collected on single slot Pioloformcoated grids.

\section{Data analysis}

Mapping labeled boutons at the light microscope. We identified and mapped at the light microscope labeled axonal boutons in dorsolateral areas 46 and 9, and the dorsolateral part of area 10 in a series of coronal sections (spaced 1 in every 10, with every other section counterstained with Nissl) ipsilateral to the injection site. We placed areal and laminar boundaries from Nissl (thionin)-stained coronal sections, based on architectonic maps (Barbas and Pandya, 1989). We first viewed the slides using a bright-field microscope (BX51; Olympus America) and scanned sections (Perfection 4990 Photo Scanner; Epson America) to qualitatively map labeled boutons within areas 10,46 , and 9 , and to identify sites with dense and sparse label.

Based on the qualitative analysis, we used quantitative stereologic sampling of labeled boutons from all sites with label to estimate their density in different layers using the optical fractionator method. This was accomplished with the aid of a computer-microscope interface using commer- cial software (StereoInvestigator; MicroBrightField), as described previously (Medalla and Barbas, 2006; Zikopoulos and Barbas, 2006, 2007). We used three to four evenly spaced (1 in every 20) Nissl-stained coronal sections through the entire extent of the part of each area with labeled boutons, and viewed sections at $1000 \times$ magnification under oilimmersion. We made separate counts for each layer or laminar group as follows: I, II-IIIa, IIIb, IV, Va, and Vb-VI. The 50- $\mu$ m-thick sections shrank to $\sim 15-30 \mu \mathrm{m}$ after histochemical processing and mounting on gelatin-coated slides. We counted boutons using an optical disector restricted to the central fraction of the tissue thickness $(11 \mu \mathrm{m})$. The top and bottom of each section (minimum of $2 \mu \mathrm{m}$ for $15 \mu \mathrm{m}$ sections) thus were used as guard zones to avoid error due to uneven tissue sectioning. The actual thickness of the mounted section was measured by the program at each counting site. The counting frame/disector size (area $=$ $40 \times 40 \mu \mathrm{m}$; height $=11 \mu \mathrm{m})$ and grid spacing $($ ranging from $100 \times 100$ to $400 \times 400 \mu \mathrm{m}$ ) were set to employ a sampling fraction to yield a coefficient of error of $\leq 5 \%$ (for review, see Gundersen et al., 1988; Howard and Reed, 1998; Schmitz and Hof, 2005). The average sampling fraction for labeled boutons was $\sim 1 / 400$ of the total volume of each area with label, based on pilot studies, as described previously (Zikopoulos and Barbas, 2006). Density of boutons per $\mu \mathrm{m}^{3}$ in each layer was calculated by dividing the number of boutons counted using the optical fractionator by the corresponding volumes estimated with the Cavalieri method. We normalized data to account for the variability of labeling due to differences in the size of the injections. This was accomplished by expressing the density of labeled boutons in each layer or laminar group as a fraction of the total density of labeled boutons from all layers of each area with label. Overall density in a given prefrontal area (all layers) was expressed as a fraction of the total density of labeled boutons from all areas examined in each injection case.

Mapping and measurement of labeled boutons and synapses. Photomicrographs of labeled boutons in prefrontal areas were captured under the light microscope using a high-resolution CCD camera (Olympus DP70). We acquired image stacks of several focal planes every $0.5 \mu \mathrm{m}$ to create pictures through the entire thickness of the sections in the $z$-axis using Image (version 1.32 $\mathrm{j}$ for Windows, $\mathrm{NIH}$ ), as described previously (Medalla and Barbas, 2006; Zikopoulos and Barbas, 2006). We created montages of images captured at low magnification $(200 \times)$ using Adobe Photoshop (CS2) to show the distribution of label throughout the depth of the cortex (layer I to the white matter) (Fig. 2). To obtain population estimates of bouton size, which is correlated with the number of synaptic vesicles (Germuska et al., 2006; Zikopoulos and Barbas, 2006), we captured images at high magnification $(1000 \times)$ of one to two random sites within a region of anterograde label in layer I and in layers II-IIIa of areas 10,46 , and 9 . Within each stack of images, we manually traced the profile of each labeled bouton to measure the major diameter using ImageJ (Fig. $2 \mathrm{Aa}$, red outlines). Our sampling included measurement of a total of $\sim 6000$ boutons per pathway $(n \sim 3000$ from layer I and $n \sim 3000$ from layers II-IIIa, from 2 to 3 cases).

To map synapses formed by prefrontal axons, we identified two to three coronal sections with dense anterograde label through areas 10, 46, and 9 based on bright-field maps. We processed for EM sections from matched rostrocaudal levels in adjacent series of sections, and cut blocks of tissue (through all layers) from sites with label in areas 10, 46, and 9. The tissue blocks were flat embedded in resin (as described above). For each pathway examined, we cut four to six small pieces of embedded tissue from layer I (extending to $\sim 200 \mu \mathrm{m}$ below the pial surface), and from the same blocks we cut four to six pieces of tissue from layers II-IIIa (extending $\sim 500 \mu \mathrm{m}$ below the top of layer II; total number of pieces of tissue: area $32 \rightarrow 10, n=10 ; 32 \rightarrow 46, n=11 ; 32 \rightarrow 9, n=10 ; 46 \rightarrow 9, n=$ 12). Each piece of tissue $(\sim 200 \times 400$ to $\sim 600 \times 400 \mu \mathrm{m})$ was then re-embedded in resin blocks and trimmed with a diamond trim tool (Diatome) to include most of the laminar depth (average block face area of $180 \times 300 \mu \mathrm{m}$ for layer I; and $460 \times 350 \mu \mathrm{m}$ for layers II-IIIa) for serial sectioning, as described previously (Medalla et al., 2007).

Ultrathin sections were examined at 60 or $80 \mathrm{kV}$ with a transmission EM (100CX JEOL). Boutons labeled with tracer were identified and photographed at $10,000 \times$ or $6600 \times$ using either a digital camera (DigitalMicrograph, Gatan) or film camera (negatives were scanned using Epson 


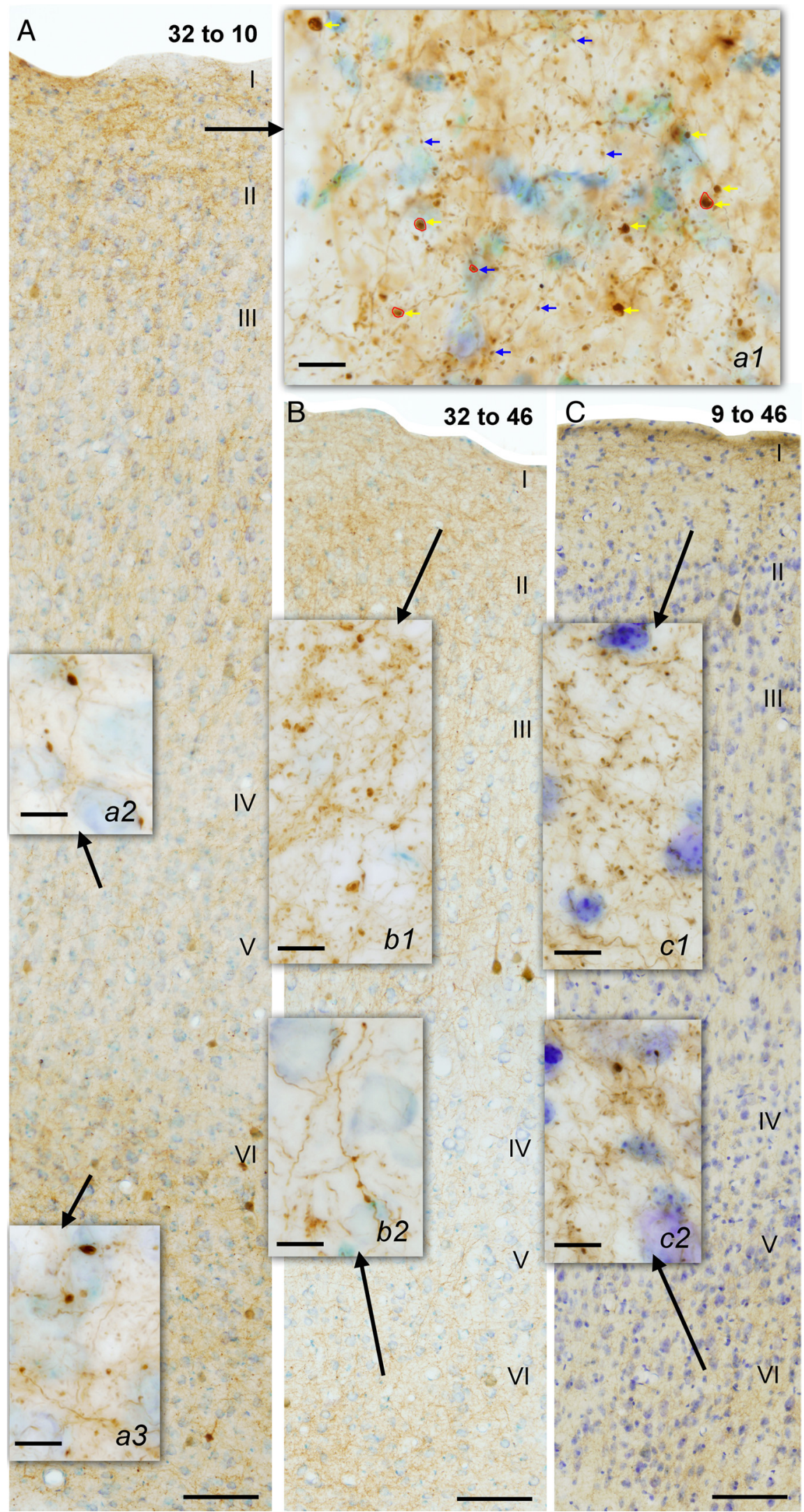

Figure 2. Photomicrographs of labeled axonal boutons from ACC (area 32) and dorsolateral pathways. A, Coronal section counterstained with Nissl (blue), through the dorsal part of area 10 shows BDA-labeled boutons (brown) from ACC (area 32) distributed throughout the depth of the cortex but are more concentrated in the upper layers (I-IIla). Laminar labels are placed at the beginning of each cortical layer. Insets show labeled fibers and boutons at higher magnification in layer I (a1), layer IV (a2), and layers V-VI (a3). a1 shows examples of large (yellow arrows) and small (blue arrows) labeled boutons. Some tracings (red outline) of labeled boutons show measurement of major diameters. $\boldsymbol{B}, \boldsymbol{C}$, Coronal sections through dorsolateral area 46 in the upper bank
Perfection 4990 Photo Scanner), from $\sim 50$ to 100 serial sections from each piece of tissue, as described previously (Medalla et al., 2007). Overall, we identified an average of $>300$ labeled boutons systematically sampled from layers I-IIIa in each pathway (1554 total boutons analyzed: $n=533$ from $32 \rightarrow 10 ; n=351$ from $32 \rightarrow 46 ; n=345$ from $32 \rightarrow 9 ; n=325$ from $46 \rightarrow 9$ ). For each pathway, we used $\sim 200$ boutons (from layers I and II-IIIa) for twodimensional (2D) analysis of major diameter, $\sim 80$ boutons (from layers II-IIIa) for threedimensional (3D) reconstruction and analysis of volume, and the rest to only identify postsynaptic targets.

For 2D analysis in the EM, we used series of $50-80$ sections and sampled exhaustively all labeled boutons in every 10 adjacent sections at intervals of $1 \mu \mathrm{m}$ (skipping $\sim 20$ sections) to yield a comparable number of data points from each pathway, as described previously (Germuska et al., 2006; Medalla et al., 2007). We used ImageJ to measure the major diameters of labeled boutons at the level of the synapse within the 10 section sampling interval. For 3D analysis, we used series of 100 sections and identified all labeled boutons in every section to yield a comparable sample of boutons from each pathway. We followed and photographed each bouton throughout the adjacent serial sections $(30-50$ sections for each synapse), and reconstructed the boutons and their postsynaptic targets in $3 \mathrm{D}$ using the open source program Reconstruct (www.bu.edu/neural) (Fiala, 2005). We estimated the thickness of sections using the method of cylindrical diameters (Fiala and Harris, 2001a). We traced object contours of boutons and postsynaptic elements manually section by section, and used the tracings to generate a 3D model and calculate volume and surface area. The 3D model was imported into 3D Studio Max (version 3, Autodesk) for additional rendering.

Analysis of postsynaptic targets and the surrounding neuropil. We used classic criteria to identify synapses with spines, which are more numerous on excitatory neurons, or with aspiny (smooth) or sparsely spiny dendritic shafts, which are characteristic of presumed inhibitory neurons in the cortex (for review, see Peters et al., 1991; Fiala and Harris, 1999). For a subset of postsynaptic spines, we followed each spine through the series to identify and analyze the parent dendrite. We measured the average cross-sectional major diameter of each dendrite, estimated spine density (number of spines per micrometer length) using stereologic methods (Fiala and Harris, 2001b), and measured the volume of the spine heads emanating from each dendrite. We identified putative inhibitory postsynaptic targets labeled

$\longleftarrow$

of the principal sulcus. Each section shows labeled boutons (brown): from area $32(\boldsymbol{B})$; and from area $9(\boldsymbol{C})$. Insets show labeled fibers and boutons in layer I (b1, $\mathbf{c}$ ) and layers $V-V$ $(\boldsymbol{b 2}, \boldsymbol{c} 2)$ at higher magnification. Scale bars: $\boldsymbol{A}-\boldsymbol{C}, 100 \mu \mathrm{m}$; $a 1-a 3, b 1, b 2, c 1, c 2,10 \mu \mathrm{m}$. 
with CB, CR, or PV by the presence of gold or TMB label found in about a fourth of the sections through the postsynaptic site in the series. CB and $\mathrm{CR}$ are expressed in a minority of pyramidal neurons (DeFelipe et al., 1989a; del Río and DeFelipe, 1997). We considered postsynaptic targets as belonging to presumed inhibitory $\mathrm{CB}, \mathrm{CR}$, or PV neurons if they were labeled, and also were aspiny or sparsely spiny. The latter were characterized by computing a density index for spines (number of spines/ $\mu \mathrm{m}$ ) and synapses (number of synapses/ $\mu \mathrm{m}$ ) of reconstructed dendrites (supplemental Fig. 1, available at www.jneurosci.org as supplemental material), as described previously (Fiala and Harris, 2001b; Medalla and Barbas, 2009). On average, smooth dendrites had a higher number of asymmetric synapses per micrometer (average: $1.4 \pm 0.1$ synapse $/ \mu \mathrm{m}$ ) compared with sparsely spiny dendrites $(0.9 \pm 0.2$ synapse/ $\mu \mathrm{m})$. The latter overlapped with spiny dendrites in terms of spine density (sparsely spiny: range $=0.2-1.0$ spines $/ \mu \mathrm{m}$; mean $=0.4 \pm 0.1$ spines $/ \mu \mathrm{m}$; spiny: range $=0.4-3$ spines $/ \mu \mathrm{m}$; mean $=1.5 \pm 0.2$ spines $/ \mu \mathrm{m})$. However, sparsely spiny dendrites had a significantly higher density of synapses on shafts, which were virtually absent on spiny dendrites, consistent with previous studies (Feldman and Peters, 1978; Kawaguchi et al., 2006; Medalla and Barbas, 2009) (for review, see Fiala and Harris, 1999). Measuring the synapse density, spine density, and diameter of dendrites helped characterize dendritic morphology but could not be used to determine whether a dendritic segment was distal or proximal.

We used stereologic methods to investigate whether labeled boutons from area 32 differed from unlabeled boutons that formed asymmetric synapses in the surrounding neuropil in areas 10 and 46 (White, 1989). We used systematic random sampling of the neuropil surrounding 1 in every 30 labeled boutons, each spanning 30-50 adjacent serial sections, in area 10 (average volume sampled $=1.65 \mathrm{~mm}^{3} ; n=6$ sites sampled, from 2 cases) and area 46 (average volume $=1.68 \mathrm{~mm}^{3} ; n=5$ sites sampled, from 2 cases). We photographed labeled boutons at the center of the frame and counted all unlabeled boutons around them $(n=1140$ boutons in area $10 ; n=1286$ in area 46 ). We reconstructed in $3 \mathrm{D}$ a subset of unlabeled boutons that were complete in the series $(n=275$ in area 10; $n=218$ in area 46 ).

Statistical analysis. For each injection site, we obtained measurements of labeled boutons from multiple sites with tracer label in areas 10, 46, and 9 , in two to three monkeys. The analysis of major diameters at the light microscope, and proportion of postsynaptic targets and 3D volumes at the EM, included measurements for the pathway from $32 \rightarrow 9$ and $46 \rightarrow 9$ reported from a previous study (Medalla and Barbas, 2009) for comparison. Statistical comparisons were made using one-way or two-way ANOVA and Bonferroni's or Tukey's post hoc test in Statistica (version 7 for Windows, StatSoft). We used linear regression using least-squares approximation in Sigma-Plot (version 7.0 for Windows, SPSS) to determine relationships between presynaptic (bouton volume) and postsynaptic features (postsynaptic density area, spine volume, and dendrite diameter). We used K-means cluster analysis on the major diameters and volumes of labeled boutons using Statistica, with parameters set to maximize initial between-cluster differences, as described previously (Zikopoulos and Barbas, 2006). The cluster analysis statistically generated a cutoff point based on the major diameters or volumes and separated the population of labeled boutons into size groups (large and small). We used the resulting groups generated by the analysis to determine the proportion of large and small boutons in each pathway.

\section{Results}

We investigated the terminations of labeled pathways from ACC area 32 to the functionally distinct dorsolateral prefrontal areas 10, 46, and 9 (Fig. 1, black arrowheads) after injection of anterograde tracers in area $32(n=4)$. For comparison, we examined pathways connecting the functionally related and neighboring dorsolateral areas 46 and 9 (Fig. $1 B$, silhouette arrowheads) $(n=4: 2$ in area 46; 2 in area 9). Figure 1 shows the injection sites within the central part of area 32 (Fig. 1 A, cases AY, BGr, BI, and BIe), in area 46 within the dorsal bank of the principal sulcus (Fig. $1 B$, cases $\mathrm{BH}$ and BIr), and the dorsal part of area 9 (Fig. $1 A, B$, cases BGl and BJ). The findings were similar across cases for each pathway examined.
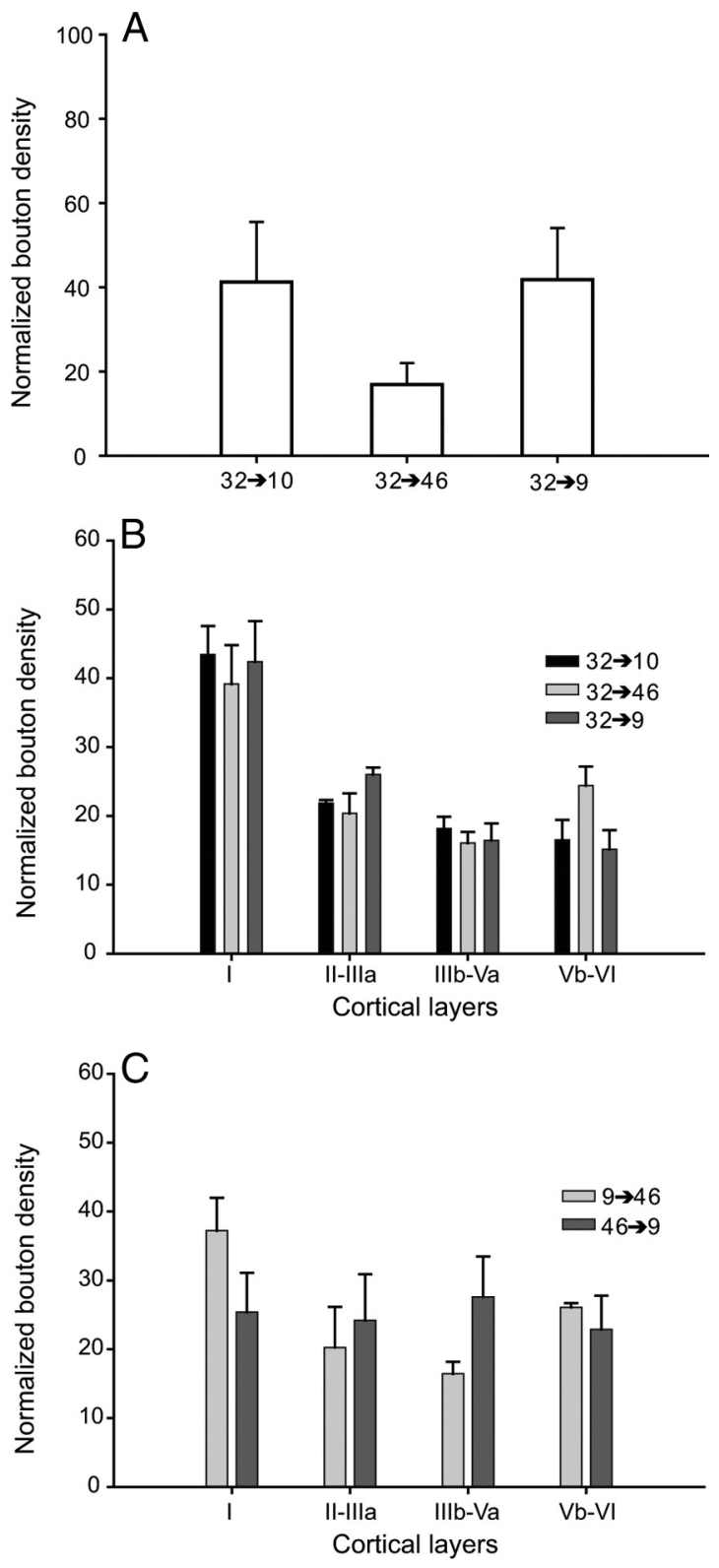

Figure 3. Distribution of labeled axonal boutons from ACC (area 32) and dorsolateral pathways. $\boldsymbol{A}, \boldsymbol{B}$, Relative regional density $(\boldsymbol{A})$ and relative laminar density $(\boldsymbol{B})$ of labeled boutons from area 32 to dorsolateral areas 10,46, and 9 . C, Relative laminar density of labeled boutons in pathways connecting the functionally related dorsolateral areas 46 and 9 . Error bars $=$ SEM.

\section{Common features of ACC (area 32) pathways}

Large boutons were prevalent in area 32 pathways to distinct dorsolateral prefrontal areas

Qualitative analysis at the light microscope showed that the axons and boutons from area 32 were widely distributed in dorsolateral prefrontal areas 10, 46, and 9. Labeled axons and boutons from area 32 spanned the entire rostrocaudal extent of the dorsolateral part of frontopolar area 10, and the anterior two-thirds of areas 46 and 9, consistent with previous findings (Barbas and Mesulam, 1985; Barbas and Pandya, 1989; Barbas et al., 1999). The labeled boutons appeared as axonal swellings, which were either terminal ("terminaux") or continuous ("en passant") varicosities along the axonal length (Fig. 2). Qualitative and quantitative analysis using unbiased stereologic methods showed that labeled boutons from area 32 were more prevalent in areas 10 and 9 than in area 46 (Fig. 3A). Labeled boutons were found in all layers but 

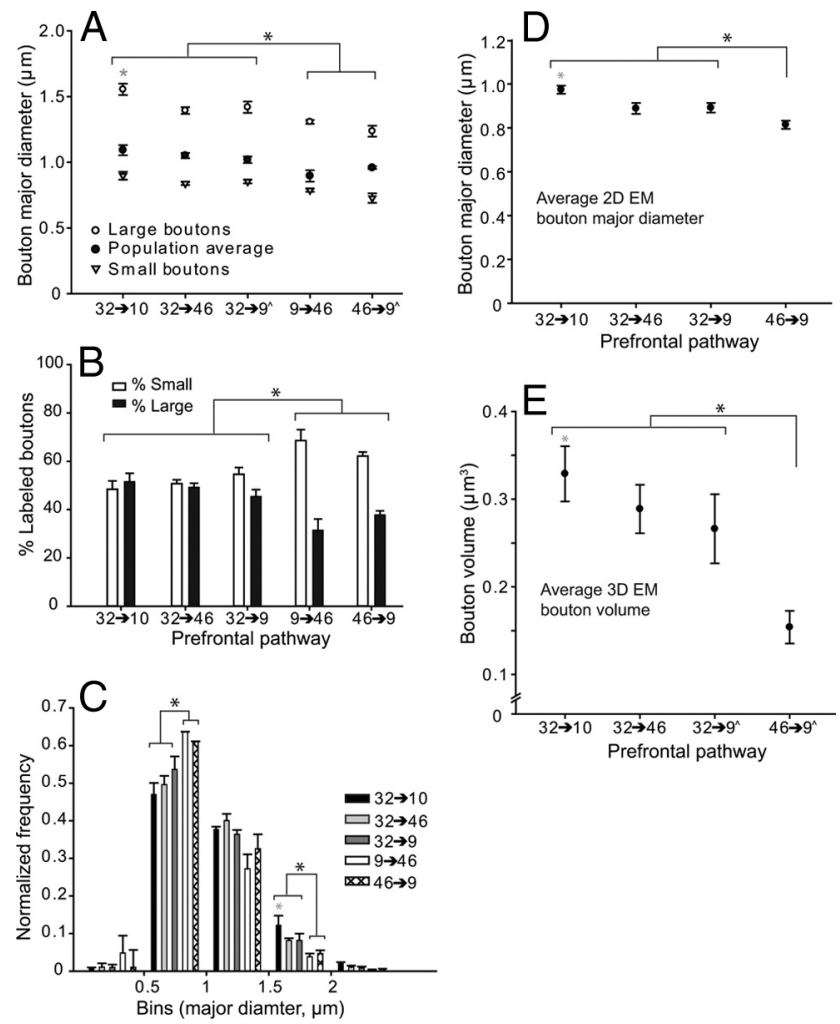

Figure 4. Axonal boutons from area 32 terminating in dorsolateral prefrontal areas are larger than in pathways connecting areas 46 and $9 . A-C$, Size of labeled boutons from area 32 $(32 \rightarrow 10,46,9)$ and dorsolateral $(9 \rightarrow 46,46 \rightarrow 9)$ pathways measured at the light microscope: average major diameters of total, large, and small labeled boutons in layers I-Illa $(\boldsymbol{A})$; proportion of small and large labeled boutons $(\boldsymbol{B})$; and normalized frequency distribution histogram of major diameters of labeled boutons (C).D,E, Size of labeled boutons measured at the EM: average major diameters of labeled boutons in layers I-IIla in all pathways measured using $2 \mathrm{D}$ electron microscopy $(32 \rightarrow 10, n=266$ boutons; $32 \rightarrow 46, n=134 ; 32 \rightarrow 9: n=180$; $46 \rightarrow 9, n=171)(\boldsymbol{D})$; and average volume of labeled boutons in layers II-Illa in all pathways from 3D serial EM analysis $(32 \rightarrow 10, n=66 ; 32 \rightarrow 46, n=102 ; 32 \rightarrow 9, n=45 ; 46 \rightarrow 9$, $n=33)(\boldsymbol{E})$. Black asterisks show significant differences between area 32 and dorsolateral pathways; gray asterisks show significant differences among the area 32 pathways to dorsolateral areas 10,46, and $9(p<0.05)$. ^Data from (Medalla and Barbas, 2009) used for comparison. Error bars $=$ SEM.

were somewhat denser in the upper cortical layers $(\sim 60 \%$ in I-IIIa) than in the middle-deep layers ( $\sim 40 \%$ in IIIb-VI). Within the upper layers, boutons were densest in layer I (Figs. $2 A, B, 3 B$ ). Boutons from pathways connecting dorsolateral areas 46 and 9 were about evenly distributed across layers (Figs. $2 C, 3 C$ ). Here, we focused analysis of synapses in layers I-IIIa, which included robust labeling in all pathways examined.

The size of boutons is positively correlated with the number of synaptic vesicles (Germuska et al., 2006; Zikopoulos and Barbas, 2007) and the probability of transmitter release with each action potential (Tong and Jahr, 1994; Murthy et al., 1997). We thus measured the size of boutons at the light microscope $(n=31,009$ total boutons measured for major diameters) and at the ultrastructural level (2D EM major diameter, $n=751$; 3D EM volume, $n=246$ total boutons). Cluster analysis segregated boutons into small (Fig. $4 A-C$, major diameters $<1.0 \mu \mathrm{m}$ at the light microscope; or Figs. $4 D, E, 5 E-G, 2 \mathrm{D}$ EM diameters $<0.94 \mu \mathrm{m}$, and 3D EM volumes $<2 \mu \mathrm{m}^{3}$ ) and large (greater than the above sizes). There was a trend for a higher prevalence of large boutons that terminated in layers II-IIIa than in layer I, consistent with previous findings (Germuska et al., 2006; Medalla et al., 2007),
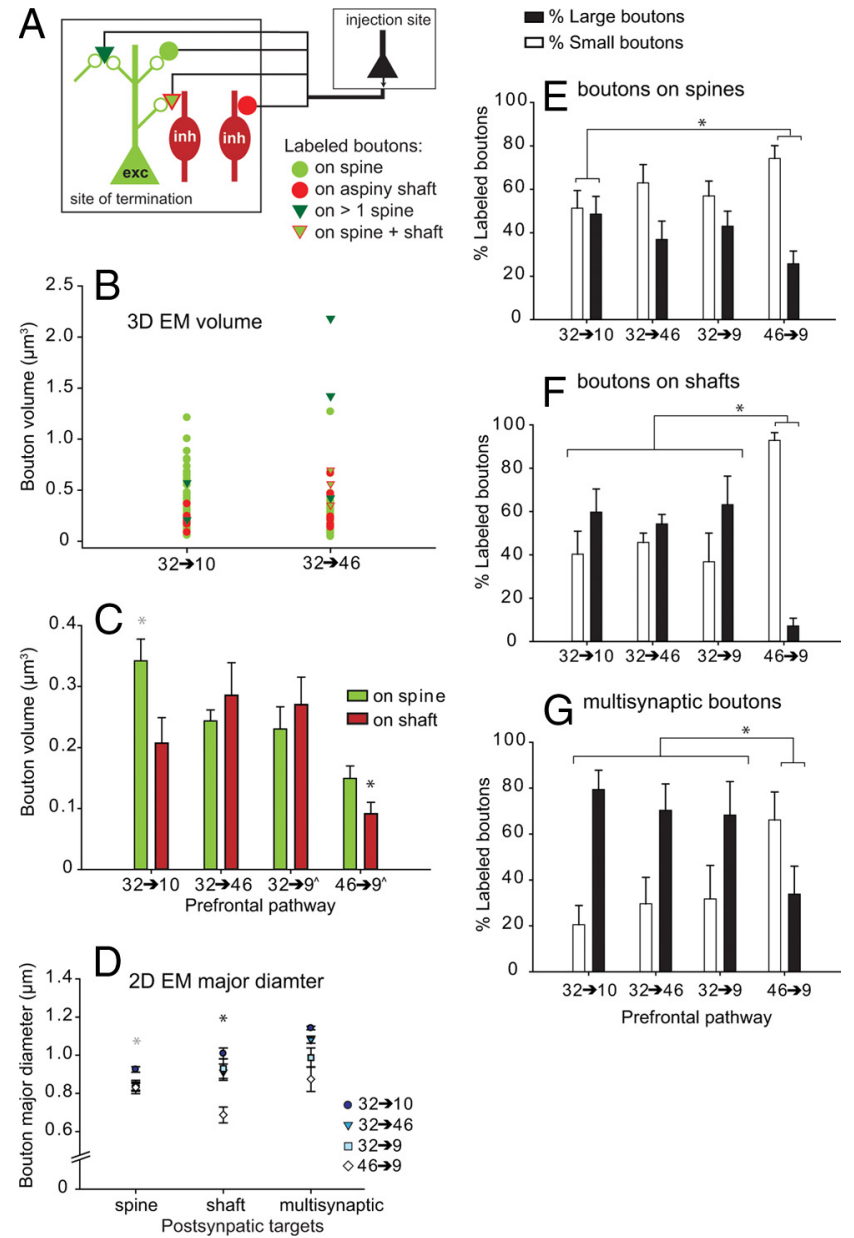

Figure 5. Large area 32 boutons target preferentially dendritic shafts of putative inhibitory neurons in all dorsolateral areas and spines of putative excitatory neurons in area 10. A, Schematic diagram shows the three main types of postsynaptic targets of labeled boutons from area 32 to dorsolateral areas. Labeled boutons form synapses with spines of presumed excitatory (exc) neurons (green filled circle), with dendritic shafts of presumed inhibitory (inh) neurons (red filled circle), or with multiple postsynaptic sites: with more than one spine (dark green triangle), or with a spine and an aspiny shaft (red-green triangle). $\boldsymbol{B}$, Scatter plot shows volumes of individual labeled boutons from area 32 with distinct postsynaptic targets in layers II-IIla of areas 10 and 46. C, Average volume of boutons that target spines (green bars) and dendritic shafts (red bars) in layers II-IIlla of all pathways. Black asterisks show significant differences between area 32 and dorsolateral pathways ( $32 \rightarrow 10,46,9$ versus $46 \rightarrow 9$ ); gray asterisks show significant differences among the area 32 pathways to distinct dorsolateral areas 10,46 , and $9(p<0.05)$. ^ Data from (Medalla and Barbas, 2009) used for comparison. D, Average major diameters of boutons with distinct postsynaptic targets in layers I-Illa, measured in $2 D$ EM. $\boldsymbol{E}-\boldsymbol{G}$, Proportions of large and small boutons with distinct postsynaptic sites based on cluster analysis of 2D (layers I-IIIa) and 3D (layers II-IIIa) EM data: $\boldsymbol{E}$, boutons forming a synapse with a spine; $\boldsymbol{F}$, boutons forming a synapse with a dendritic shaft; $\boldsymbol{G}$, boutons with multiple postsynaptic targets. Error bars $=$ SEM.

but the laminar differences were not statistically significant in all pathways examined so data from the upper layers (I-IIIa) were pooled.

Boutons from area 32 that terminated in areas 46, 9, and, especially area 10 , were larger than in pathways connecting the related dorsolateral areas 46 and 9. The difference was due to greater overall size ( $p<0.05$, ANOVA, post hoc test) (Fig. $4 A, D, E)$, as well as the proportion of large boutons $(p<0.01)$ (Fig. $4 B, C$ ). Large boutons were associated with large postsynaptic density (PSD) areas on spines $\left(R^{2}=0.41\right)$ and dendritic shafts $\left(R^{2}=0.42, p<0.01\right)$ (supplemental Fig. 2, available at www. jneurosci.org as supplemental material). The pathways from area 
32 to distinct dorsolateral areas had in common larger boutons than in the pathways connecting the neighboring dorsolateral areas 46 and 9.

Area 32 boutons formed large synapses with putative inhibitory neurons in distinct dorsolateral prefrontal areas Further analysis at the ultrastructural level revealed that the differences in bouton size across pathways were related to the type of postsynaptic target (Fig. 5A,B), confirming and extending previous findings (Medalla and Barbas, 2009). Like other prefrontal pathways, boutons from area 32 mainly innervated single spines of presumed excitatory neurons in all dorsolateral areas examined ( $\sim 58-80 \%)$ (Figs. $6 A, 7 A, B, 8 A$; supplemental Table 1 , available at www.jneurosci.org as supplemental material). A smaller but significant proportion of boutons innervated aspiny (or sparsely spiny) dendritic shafts of presumed inhibitory neurons $(\sim 13-27 \%)$ (Figs. $6 E, F, 7 D-I$, $8 A$ ), or multiple postsynaptic sites of either two or more spines ( $\sim 5-8 \%$ ) (Figs. $6 B, C, 7 C, 8 A)$ or a spine and a dendritic shaft $(\sim 3-8 \%)$ (Figs. $6 D, 7 J, 8 A)$. The pathways from area 32 to dorsolateral areas 10, 46, and 9 included in common significantly larger boutons that innervated putative inhibitory neurons, compared with the pathway connecting the related dorsolateral areas $46 \rightarrow 9$ ( $p<0.05$ ) (Fig. $5 C$, red bars, $D)$. There was a similar trend for single boutons that innervated multiple postsynaptic sites (Fig. 5D). About half of the dendritic shaft-targeting boutons (Fig. $5 F$ ) and $\sim 80 \%$ of multisynaptic boutons (Fig. 5G) from area 32 to dorsolateral areas $(10,46$, and 9) were large (2D EM major diameter $\geq 0.94 \mu \mathrm{m}$; $3 \mathrm{D}$ EM volumes $\geq 2 \mu \mathrm{m}^{3}$ ). In contrast, most dendritic shaft-targeting ( $~ 90 \%)$ and multisynaptic ( $\sim 65 \%)$ boutons from dorsolateral area 46 to area 9 were small (major diameters $<0.94 \mu \mathrm{m}$; volumes $<2$ $\left.\mu \mathrm{m}^{3}\right)$. The high prevalence of large boutons that innervated either dendritic shafts of presumed inhibitory neurons or multiple postsynaptic sites is a feature that distinguished the ACC (area 32) pathways to dorsolateral areas 10, 46, and 9 from the pathways that connect the related dorsolateral areas 46 and 9.

\section{Specialized synaptic features of ACC (area 32) pathways to} dorsolateral areas $\mathbf{1 0}$ and $\mathbf{4 6}$

Area 32 boutons formed large synapses with spines in area 10 Beyond the above common features of ACC (area 32) pathways to distinct dorsolateral areas, the ACC pathway to area $10(32 \rightarrow$ 10) was distinguished further by large boutons that innervated spines of presumed excitatory neurons $(p<0.05)$ (Figs. $5 C$, green bar with asterisk, $5 D, E, 6 A, B, 7 A)$. These large area 32

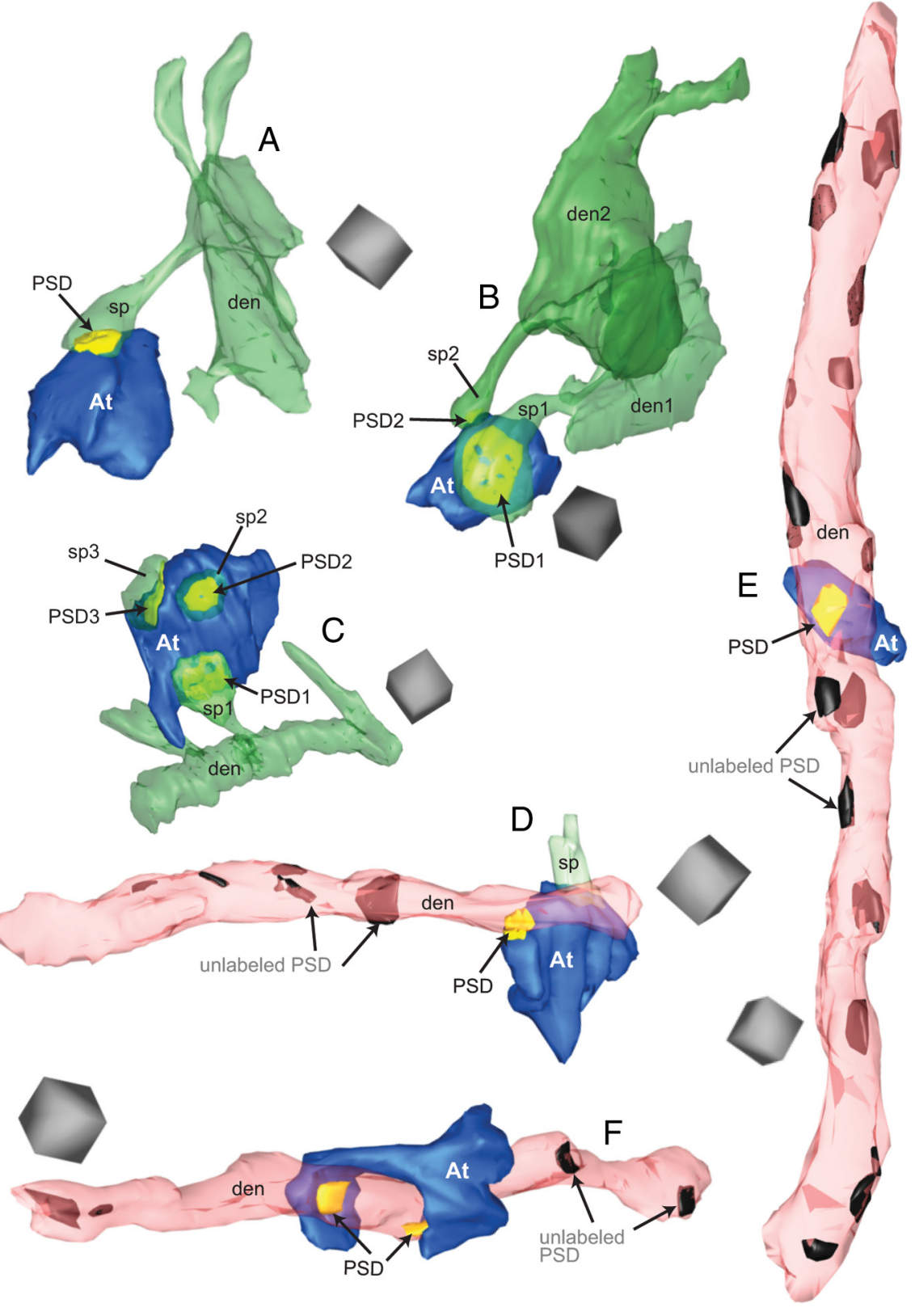

Figure 6. Examples of synapses formed by ACC (area 32) in areas 10 and 46 reconstructed in 3D. A, A large bouton (axon terminal, At, blue) from area 32 forms a synapse (postsynaptic density, PSD, yellow) on a spine (sp) in area 10 that branches from a dendrite (den, green). $\boldsymbol{B}-\boldsymbol{D}$, Large multisynaptic boutons (At): $\boldsymbol{B}$, bouton forms synapses (PSD1 and 2) with two spines (sp1 and 2, branching from den 1 and 2) in area 10; $\boldsymbol{C}$, bouton forms synapses (PSD1-3) with three spines (sp1-3) in area 46, sp1 branches from dendrite (den); $\boldsymbol{D}$, bouton forms one synapse with a spine (sp) and another with an aspiny dendrite of a presumed inhibitory neuron (den, pink translucent) in area 46. $\boldsymbol{E}, \boldsymbol{F}$, Large boutons (At) from area 32, each forming a synapse with an aspiny dendrite of a presumed inhibitory neuron in area 46 . In $\boldsymbol{D}-\boldsymbol{F}$, note the prevalence of unlabeled synapses (gray patches) scattered throughout the surface of each aspiny dendrite reconstructed in 3D, with some located on the foreground (appearing dark gray) and others on the back surface visible through the translucent dendrite (appearing gray-purple). Scale cube $=0.5 \mu \mathrm{m}^{3}$.

boutons exceeded in size even boutons that innervated dendritic shafts of presumed inhibitory neurons in all other pathways examined $(p<0.05)$ (Fig. 5C, compare red and green bars). This synaptic specialization accounted for the overall larger size of boutons from area 32 to area 10 evident at the population level (Fig. 4), and provided a sharp contrast to the other pathways examined because spines were the majority of postsynaptic targets. Spines are the most prevalent targets in other corticocortical pathways as well (Anderson et al., 1998; Melchitzky et al., 1998, 2001; Anderson and Martin, 2002, 2005, 2006; Medalla et al., 

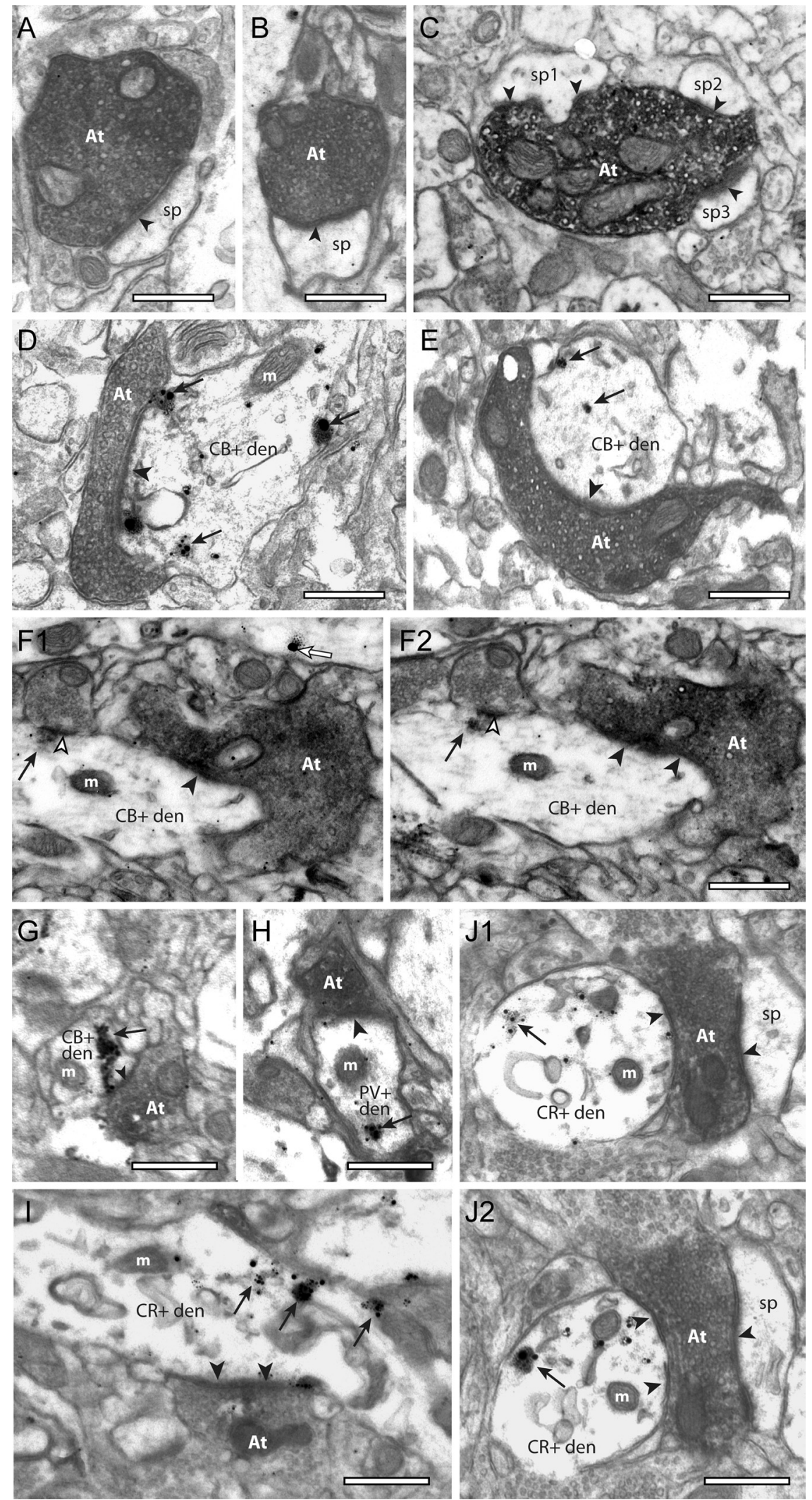

Figure 7. Electron photomicrographs of boutons from ACC (area 32) and their synapses in areas 10 and $46 . \boldsymbol{A}, \boldsymbol{B}, \mathrm{FE}-$ labeled boutons (axon terminal, At) from area 32, each forming a synapse (black arrowhead) with a spine (sp): large bouton in area $10(\boldsymbol{A})$ small bouton in area $46(B)$. C, A large multisynaptic bouton (At) labeled with BDA forms synapses with three spines (sp1-3) in area 46. D, A large FE-labeled bouton (At) forms a synapse (black arrowhead) with a $C B+$ dendrite $(C B+$ den), which has mitochondria (m) and is labeled with silver-enhanced gold (black arrows) in area 10. E-I, Labeled boutons (At) from area 32 that form synapses (black arrowheads) with dendritic shafts of presumed inhibitory neurons in area 46. $\boldsymbol{E}$, A large BDA-labeled bouton (At) forms a
2007) (for review, see White, 1989; Callaway, 1998; Somogyi et al., 1998; Douglas and Martin, 2004). These findings suggest stronger innervation of presumed excitatory neurons in the pathway from area 32 to area 10 than to dorsolateral areas 46 and 9.

Area 32 boutons innervated more presumed inhibitory postsynaptic sites in area 46

The ACC pathway to area $46(32 \rightarrow 46)$ showed a different specialization by forming significantly more synapses with presumed inhibitory neurons $(\sim 33 \%$ of all synapses) than in the other pathways $(p<0.05 ; \sim 23 \%$ in $32 \rightarrow 10, \sim 22 \%$ in $32 \rightarrow 9)$. As described above, area 32 innervated a higher proportion of dendritic shafts of presumed inhibitory neurons in all pathways examined $(32 \rightarrow 10,32 \rightarrow 46$, $32 \rightarrow 9)$ than in the pathway connecting the related dorsolateral areas $46 \rightarrow 9$ ( $p<$ 0.05) (Fig. $8 A$, black asterisk), but this pattern was most pronounced for the pathway from area 32 to area $46(32 \rightarrow 46)$ (Figs. $7 E-I, 8 A$, gray asterisk). The targeted dendrites of presumed inhibitory neurons in all pathways were mostly aspiny (Fig. $6 E, F)$, but some $(\sim 24 \%)$ were sparsely spiny with a relatively high density of asymmetric synapses on their shafts (supplemental Fig. 1, available at www. jneurosci.org as supplemental material).

Most $(\sim 57-78 \%)$ of the innervated dendrites of presumed inhibitory neurons were also labeled for one of the calciumbinding proteins, $\mathrm{CB}, \mathrm{CR}$, or PV (Fig. $7 D$ $J$ ). Axonal boutons from area 32 formed synapses with a higher proportion of $\mathrm{CB}$ positive dendrites $(\sim 6-10 \%$ of all targets, $\sim 47 \%$ of neurochemical targets) than the pathway from dorsolateral area 46 to area 9 ( $p<0.05 ; \sim 4 \%$ of all targets, $\sim 26 \%$ of neurochemical targets) (Figs. $7 D-G, 8 B$, dark gray). Innervation of CR (4-9\% of all

synapse with a $C B+$ dendrite $(C B+$ den) labeled with gold (black arrows). F1, F2, Two consecutive images of a large FElabeled bouton (At) that forms a synapse (black arrowheads) with a $C B+$ dendrite labeled with TMB (black arrows), which also receives synapses from unlabeled boutons (silhouette arrowheads). In $\boldsymbol{F 1}$, note the nearby dendrite with gold labe (silhouette arrow) in the surrounding neuropil in triplelabeled tissue. G, A small bouton (At) forms a synapse with a $\mathrm{CB}+$ dendrite labeled with TMB (black arrow). $\boldsymbol{H}$, A small bouton (At) forms a synapse with a PV + dendrite (PV + den) labeled with gold (black arrow). I, A large bouton (At) lightly labeled with FE forms a synapse with a $\mathrm{CR}+$ dendrite $(\mathrm{CR}+$ den) labeled with gold (black arrows). J1, J2, Two consecutive images show a large FE-labeled multisynaptic bouton in area 10 (At) forming one synapse with a spine (sp) and another synapse with a $C R+$ dendrite $(C R+$ den) labeled with gold (black arrows). Scale bars, $0.5 \mu \mathrm{m}$. 

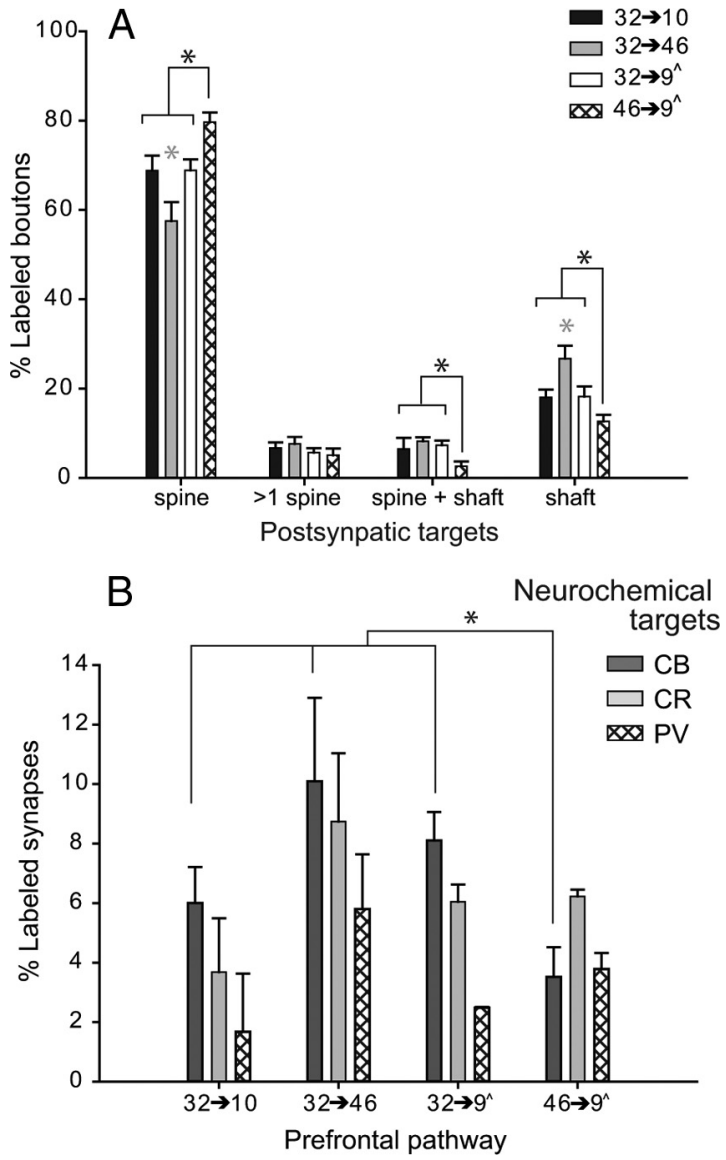

Figure 8. Synapses with presumed inhibitory postsynaptic sites were most prevalent in the area 32 pathway to dorsolateral area 46 . A, Proportion of labeled boutons in area $32(32 \rightarrow 10$, $46,9)$ and dorsolateral $(46 \rightarrow 9)$ pathways that formed synapses with specific postsynaptic elements presumed to be excitatory (spines) or inhibitory (shafts). $\boldsymbol{B}$, Proportion of synapses with putative inhibitory neurons labeled with $\mathrm{CB}, \mathrm{CR}$, or PV. Black asterisks show significant differences between area 32 and dorsolateral pathways; gray asterisks (in $\boldsymbol{A}$ ) show significant differences among the area 32 pathways to distinct dorsolateral areas 10,46 , and $9(p<0.05)$. $\wedge$ Data from (Medalla and Barbas, 2009) used for comparison. Error bars $=$ SEM.

targets) (Figs. 7 I, J, 8 B, light gray) and PV (2-6\% of all targets) (Figs. $7 \mathrm{H}, 8 \mathrm{~B}$, crosshatch) positive dendrites was comparable in the pathways examined. Axons from area 32 formed synapses with a significant proportion of $\mathrm{CR}$ positive dendrites $(\sim 35 \%$ of neurochemical targets), but synapses with PV postsynaptic sites were fewer $(\sim 18 \%$ of neurochemical targets) than for $\mathrm{CB}$ or $\mathrm{CR}$ in all areas examined $(10,46$, and 9$)$. Area 32 axons innervated all three neurochemical classes of presumed inhibitory neurons more frequently in area 46 than in areas 10 and 9, consistent with the overall higher prevalence of area 32 synapses with putative inhibitory postsynaptic sites in area 46.

\section{Pathway-specific distinction of ACC (area 32) boutons from surrounding unlabeled boutons}

The neuropil in the vicinity of synapses from labeled area 32 axonal boutons in areas 10 and 46 had a comparable distribution of unlabeled synapses with spines and dendritic shafts $(p>0.05)$ (Fig. 9A, silhouette bars; supplemental Table 1, available at www. jneurosci.org as supplemental material). This evidence suggests that areas 46 and 10 have similar microcompartments (White, 1989). Moreover, in area 10, unlabeled synapses were similar to labeled synapses from area 32 with respect to the proportion of specific postsynaptic targets (Fig. 9A, compare black and silhouette bars). On
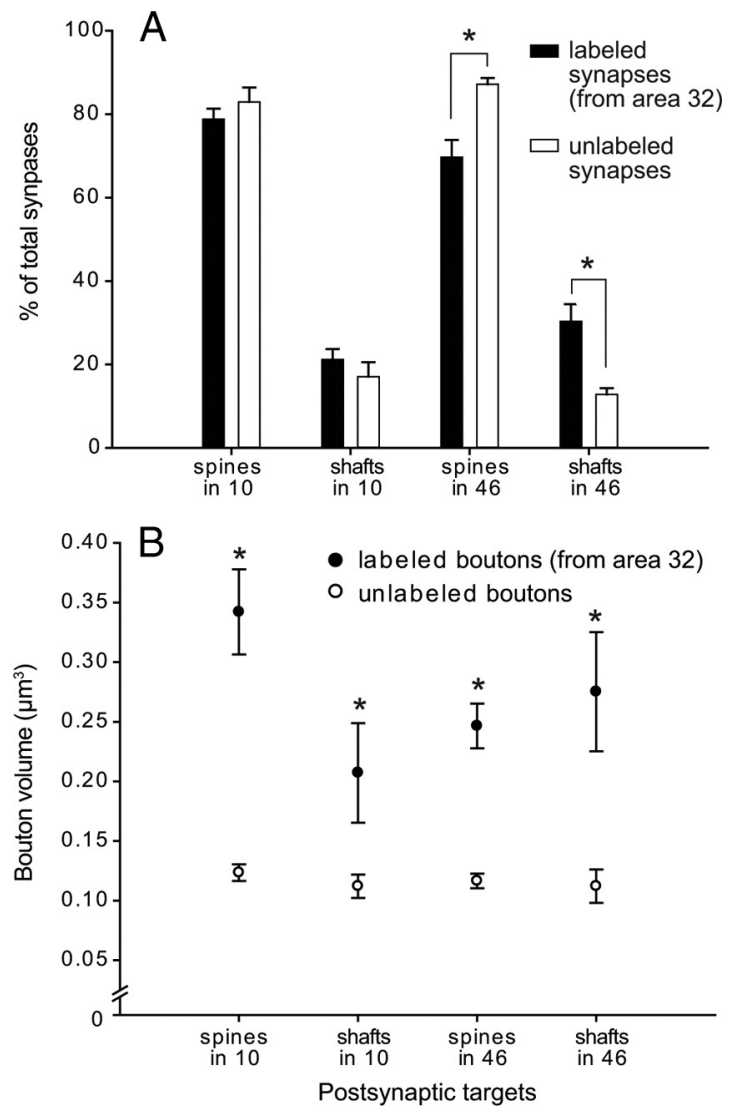

Figure 9. Comparison of synapses from area 32 with the surrounding neuropil in layers II-IIIa of areas 10 and 46. $A$, Proportion of synapses on spines and dendritic shafts. Labeled synapses formed by area 32 boutons in area 46 differed significantly from unlabeled synapses in the surrounding neuropil ( ${ }^{*} p<0.01$ ), but not in area $10 . \boldsymbol{B}$, Volumes of labeled boutons from area 32 were significantly larger $\left({ }^{*} p<0.01\right)$ than nearby unlabeled boutons in areas 10 and 46 , especially for boutons forming synapses with spines in area 10 . Error bars $=$ SEM.

the other hand, in area 46, labeled boutons from area 32 formed synapses more often on dendritic shafts of presumed inhibitory neurons than the unlabeled synapses in the surrounding neuropil ( $p<$ 0.01) (Fig. 9A, asterisks).

In addition, labeled boutons from area 32 were significantly larger in volume than unlabeled boutons in the surrounding neuropil in both areas 46 and 10, especially boutons that targeted spines in area $10(p<0.01)$ (Fig. 9B; supplemental Table 1 , available at www.jneurosci.org as supplemental material). A similar pattern was seen for individual segments of aspiny (presumed inhibitory) (Fig. 10A,C,D) and spiny (presumed excitatory) dendrites targeted by area 32 boutons (Fig. $10 B, E-G$ ). PSDs and spines that were innervated by labeled boutons from area 32 were larger than those innervated by nearby unlabeled boutons even within the same dendritic segment $(p<0.05)$ (Fig. 10 A, B, asterisks). In contrast, there were no significant differences in the size of presynaptic and postsynaptic elements between labeled and unlabeled boutons in the pathway connecting the two related dorsolateral areas 46 and 9 ( $p>0.05)$. Interestingly, in all pathways studied, spines that were innervated by labeled boutons were situated on parent dendrites that had overlapping spine densities and diameters (supplemental Fig. 3, available at www. jneurosci.org as supplemental material). This evidence suggests that all pathways studied targeted morphologically similar spiny dendritic segments (Larkman, 1991) but varied in the volume of the innervated spines, which were largest in the pathway from 

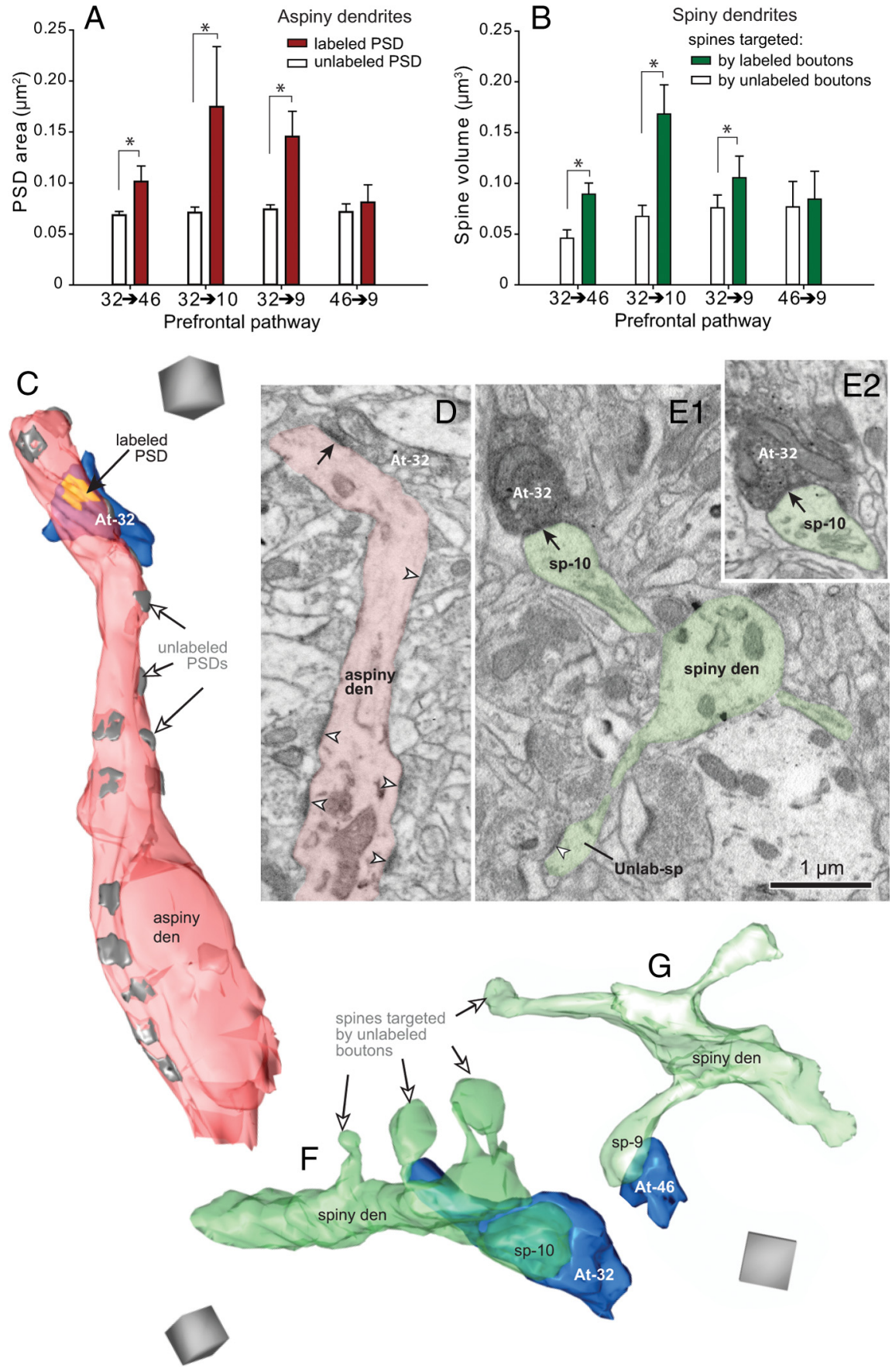

Figure 10. Postsynaptic elements innervated by labeled area 32 boutons were larger than unlabeled boutons targeting the same dendritic segment in dorsolateral prefrontal areas. $\boldsymbol{A}$, Labeled (red bars) and unlabeled (silhouette bars) boutons and the average surface area of their associated PSDs on shafts of the same aspiny/sparsely spiny dendrite of presumed inhibitory neurons. $\boldsymbol{B}$, Average volumes of spines innervated by labeled (green bars) and unlabeled (silhouette bars) boutons on the same spiny dendrites of presumed excitatory neurons. PSDs and spines that were innervated by labeled boutons from ACC area 32 were significantly larger $\left({ }^{*} p<0.05\right)$ than those innervated by nearby unlabeled boutons. Error bars $=$ SEM. C, D, 3D reconstruction (C) and EM photomicrograph $(\boldsymbol{D})$ of an aspiny dendrite (aspiny den, pink) receiving a synapse (yellow in $\boldsymbol{C}$; black arrows in $\boldsymbol{C}$ and $\boldsymbol{D}$ ) from a labeled bouton or axon terminal from area 32 (At-32; blue in $C$. The aspiny dendrite also receives synapses from nearby unlabeled boutons (gray patches and silhouette arrows in (; silhouette arrowheads in D).E1, E2, Photomicrographs of adjacent sections show a large labeled bouton from area 32 (At-32) forming a synapse (black arrow) with a large spine in area 10 (sp-10) that branches from a dendrite (spiny den, green). Note the smaller nearby spine (Unlab-sp) branching from the same dendrite and forming a synapse (silhouette arrowhead) with an unlabeled bouton. $\boldsymbol{F}, \mathbf{G}, 3 \mathrm{D}$ reconstructions of spines branching from spiny dendrites targeted by labeled boutons in prefrontal pathways: A labeled bouton from area 32 (At-32, blue) forms a synapse with a spine in area 10 (sp-10, green) $(\boldsymbol{F})$, which is larger than the nearby spines targeted by unlabeled boutons (silhouette arrows) and branching from the same spiny dendrite (spiny den, green); and a labeled bouton from dorsolateral area 46 (At-46, blue) forms a synapse with a spine in area 9 (sp-9, green) $(\mathbf{G})$, which is comparable in size to nearby spines targeted by unlabeled boutons. Scale cube $=0.5 \mu \mathrm{m}^{3}$. area 32 to area 10 (Fig. $10 \mathrm{~B}$ ). These findings further highlight the higher prevalence of ACC (area 32) innervation of dendritic shafts of putative inhibitory neurons in area 46, and specialized large axonal boutons that formed synapses with spines of putative excitatory neurons in area 10 , which stood apart from synapses in the surrounding neuropil.

\section{Discussion}

\section{Common features of ACC synapses in} several dorsolateral prefrontal areas The pathways from ACC (area 32) to layers I-IIIa of dorsolateral areas 10, 46, and 9 had in common a higher prevalence of large boutons, compared with pathways connecting neighboring dorsolateral areas 46 and 9. The significance of this feature is based on evidence that large boutons have more vesicles (Germuska et al., 2006; Zikopoulos and Barbas, 2007), a feature correlated with a higher probability of neurotransmitter release with each action potential (Tong and Jahr, 1994; Murthy et al., 1997). Further, large boutons form synapses with large postsynaptic densities, which have more receptors (for review, see Nimchinsky et al., 2002; Bourne and Harris, 2008). This combination of presynaptic and postsynaptic features leads to increased synaptic efficacy (Murthy et al., 2001).

In particular, large boutons from area 32 preferentially innervated in common presumed inhibitory neurons in areas 46 , 9 and 10 , consistent with previous findings (for area 32 to 9, see Medalla and Barbas, 2009). This evidence suggests that the ACC engages efficiently inhibitory mechanisms, which are thought to help reduce noise in dorsolateral prefrontal areas (Wang et al., 2004; Medalla and Barbas, 2009), consistent with functional studies (MacDonald et al., 2000; Badre and Wagner, 2004; Johnston et al., 2007; Mitchell et al., 2007; $\mathrm{Ng}$ et al., 2007; Brown and Braver, 2008; Chen et al., 2008; Mulert et al., 2008). Beyond these common synaptic features, area 32 axons had specialized synapses in areas 46 and 10, as elaborated below.

\section{The ACC targeted preferentially distinct postsynaptic elements of areas 46 and 10}

Area 32 axons showed two area-specific synaptic interactions. The first was a significantly higher prevalence of synapses with presumed inhibitory neurons in area 46 , compared with areas 9 or 10 , or between areas 46 and 9. The second was preferential innervation of spines in area 


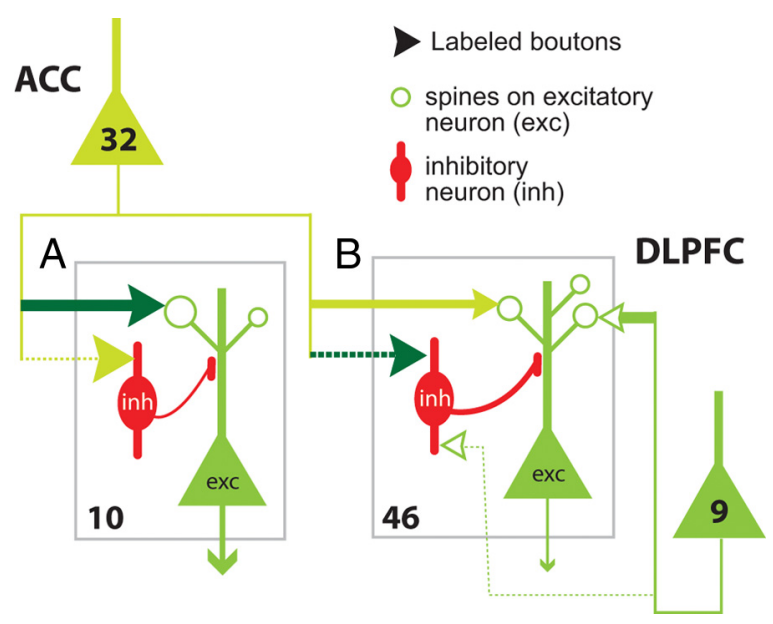

Figure 11. Summary circuit of distinct synaptic area 32 pathways to dorsolateral prefrontal cortex (DLPFC). The schematic highlights the main findings, showing the common and unique synaptic features of ACC (area 32) pathways to distinct dorsolateral prefrontal areas 10 and 46 (light and dark green filled arrows). Line thickness represents prevalence of pathways, and size of arrowhead represents size of boutons. ACC (area 32) pathways innervated presumed inhibitory neurons (inh, red) in all dorsolateral areas with large boutons (filled arrows with dotted lines), distinguishing them from pathways within dorsolateral prefrontal cortex (area $46 \rightarrow 9$, light green open arrows). $\boldsymbol{A}$, The ACC (area 32) pathway to area 10 was distinguished by large boutons (dark green, larger arrowhead) on spines of putative excitatory neurons (light green open circles), poised to enhance excitation. $\boldsymbol{B}$, The ACC (area 32) pathway to area 46 was distinguished by more prevalent synapses (dark green, thicker dotted line) on putative inhibitory neurons, poised to enhance inhibition.

10 through large boutons, a feature not previously seen for other prefrontal pathways (Medalla and Barbas, 2009). The large boutons that innervated spines in layers I-IIIa of area 10 formed synapses that were comparable in size to "driving" cortical pathways that transmit signals efficiently (Anderson et al., 1998; Anderson and Martin, 2002, 2005). This evidence belies the widely held view that the upper cortical layers, and especially layer I, are uniformly associated with "feedback" or "modulatory" input (for review, see Felleman and Van Essen, 1991). Rather, distinct corticocortical pathways may show synaptic specificity, even when they innervate the same area and layer, which may reflect their functional specialization.

Specifically, dorsolateral areas 46 and 9 are involved when one must remember information momentarily to perform a task with sequential components (for review, see Miller and Cohen, 2001; Curtis and D'Esposito, 2004; Müller and Knight, 2006; Tanji and Hoshi, 2008), such as cooking. But suppose that while cooking, a visitor interrupts. Frontopolar area 10 is recruited when juggling multiple tasks (Koechlin et al., 1999; Burgess et al., 2000; Braver et al., 2003; Dreher et al., 2008; Tsujimoto et al., 2010), keeping on hold the main goal (cooking) to momentarily direct attention to the visitor. Sustained multitask representations are thought to be mediated by excitatory connections within dorsolateral prefrontal cortex (Wang, 1999; González-Burgos et al., 2000; Constantinidis et al., 2001), and specifically between areas 46 and 10 (Koechlin et al., 2003; De Pisapia et al., 2007), but the mechanism is unknown. The specific synapses from area 32 may be key for this process, consistent with ACC-mediated attentional and multitask functions (Gehring and Knight, 2000; Koechlin et al., 2000; Ito et al., 2003; Badre and Wagner, 2004; Emeric et al., 2008). Area 32 terminals may thus engage presumed excitatory neurons in area 10, involved in selecting and sustaining multiple tasks, and at the same time modulate activity in area 46 through CB inhibitory neurons, as summarized in Figure $11 A, B$ (dark green arrows). CB inhibitory neurons innervate the distal dendrites of pyramidal neurons (DeFelipe et al., 1989a; Kawaguchi and Kubota, 1997; Peters and Sethares, 1997), a pattern that is well suited to suppress noise at the fringes of active neurons during working memory tasks, based on physiologic and computational studies (Wang et al., 2004; Zaitsev et al., 2005). Preferential innervation of CB (and presumed inhibitory) neurons in area 46 by area 32 axons may help defer temporarily the main goal (e.g., cooking) in multitask operations. In contrast, engagement of the powerful perisomatic inhibition of pyramidal neurons by PV inhibitory neurons (Somogyi et al., 1983; DeFelipe et al., 1989b) could lead to catastrophic forgetting of the deferred goal (e.g., burn the food). Interestingly, area 32 innervation of PV neurons was far less frequent in the upper layers of areas 9,46 , or 10 , but was the most common innervation pattern in the upper layers of auditory association cortex (Medalla et al., 2007). Pyramidal neurons with sustained activity during working memory tasks (Wang, 1999; González-Burgos et al., 2000; Constantinidis et al., 2001) and CB inhibitory neurons are most prevalent in the upper layers (Condé et al., 1994; Gabbott and Bacon, 1996; Dombrowski et al., 2001), the same layers of areas 9,46 , and 10 that receive projections from ACC (Barbas and Rempel-Clower, 1997). The upper layers of area 46 are also preferentially affected in age-related cognitive decline (for review, see Luebke et al., 2010).

\section{Relationship of prefrontal cortices with auditory association areas}

Areas 32, 10, 46, and 9 have in common robust connections with auditory association cortices (Barbas and Mesulam, 1985; Petrides and Pandya, 1988; Barbas et al., 1999; Hackett et al., 1999; Romanski et al., 1999; Medalla et al., 2007) and show significant metabolic (2-deoxyglucose) activation in response to auditory stimuli (Poremba et al., 2003). Microstimulation of ACC areas 32 and 25 evokes species-specific vocalization in monkeys and affects activity in auditory cortices (Müller-Preuss et al., 1980; Müller-Preuss and Ploog, 1981) (for review, see Vogt and Barbas, 1988). In humans, correlated gamma-band activity in ACC and auditory areas suggests functional coupling between these cortices (Mulert et al., 2007). Moreover, the relative activation of ACC and auditory cortices distinguishes actual from inner speech in humans, in functions that are disrupted in schizophrenic patients who experience auditory hallucinations (Frith et al., 1995; McGuire et al., 1995).

Among prefrontal cortices, area 10 has the strongest connections with anterior and posterior auditory association cortices (Barbas and Mesulam, 1985; Medalla et al., 2007), mapped physiologically in monkeys (Rauschecker et al., 1997; Poremba et al., 2004). These connections are comparable in strength and extent to the connections of the frontal eye fields with visual association cortices (for review, see Barbas et al., 2002; Lynch and Tian, 2006). Here, we showed that area 10 receives dense and potentially strong synaptic projections from area 32, which is also robustly connected, and functionally coupled, with auditory association cortices. These pathways may help select relevant auditory stimuli and suppress noise, allowing communication even in a noisy environment (for review, see Conway et al., 2001; Denham and Winkler, 2006; Jääskeläinen et al., 2007; Micheyl et al., 2007).

Similar mechanisms may apply for keeping track of internal thoughts during working memory and problem solving tasks (Brewin and Smart, 2005) (for review, see Wenzlaff and Wegner, 2000). This hypothesis is consistent with findings that the ACC and area 10 are activated during mental tracking of multiple tasks 
(for review, see Burgess et al., 2007). Area 10 may have a role in symbolic representation of information in organized thought, aided by ACC, which also has a role in monitoring inner thoughts (McGuire et al., 1996; Wyland et al., 2003). Combined behavioral and functional studies that employ auditory-related tasks are needed to investigate the role of auditory input, and the specialized projections from area 32, to cognitive processing in area 10.

Pathology in ACC and dorsolateral prefrontal cortices is thought to disrupt the balance of excitation and inhibition in schizophrenia (for review, see Benes, 2000; Volk and Lewis, 2002; Beasley et al., 2002; Vogels and Abbott, 2007; Fornito et al., 2009; Eisenberg and Berman, 2010). For example, the ACC shows reduced activity in schizophrenia (Fletcher et al., 1999; Kerns et al., 2005; Snitz et al., 2005; Allen et al., 2007; Leicht et al., 2010). Based on the synaptic circuits here, and previous findings in nonhuman primates (Medalla and Barbas, 2009), we suggest that pathologic hypofunction in ACC may weaken its output to the neurochemical class of CB inhibitory neurons in areas 9, 46, and 10, which are thought to suppress noise (Wang et al., 2004). In addition, hypofunction in ACC may reduce excitation of frontopolar area 10, which is engaged when tackling multiple tasks and keeping track of internal thoughts. Weakening of ACC output from area 32 may thus account for the high distractibility as well as the disordered thought patterns described for schizophrenic patients (for review, see Cohen et al., 1996; Honey and Fletcher, 2006; Allen et al., 2008). While these relationships may not be easily extrapolated from monkeys to humans, the specific synaptic interactions found here provide the circuit basis to test these hypotheses in behavioral and functional studies in normal and schizophrenic subjects.

\section{References}

Allen P, Amaro E, Fu CH, Williams SC, Brammer MJ, Johns LC, McGuire PK (2007) Neural correlates of the misattribution of speech in schizophrenia. Br J Psychiatry 190:162-169.

Allen P, Larøi F, McGuire PK, Aleman A (2008) The hallucinating brain: a review of structural and functional neuroimaging studies of hallucinations. Neurosci Biobehav Rev 32:175-191.

Anderson JC, Martin KA (2002) Connection from cortical area V2 to MT in macaque monkey. J Comp Neurol 443:56-70.

Anderson JC, Martin KA (2005) Connection from cortical area V2 to V3 A in macaque monkey. J Comp Neurol 488:320-330.

Anderson JC, Martin KA (2006) Synaptic connection from cortical area V4 to V2 in macaque monkey. J Comp Neurol 495:709-721.

Anderson JC, Binzegger T, Martin KA, Rockland KS (1998) The connection from cortical area V1 to V5: a light and electron microscopic study. J Neurosci 18:10525-10540.

Badre D, D'Esposito M (2009) Is the rostro-caudal axis of the frontal lobe hierarchical? Nat Rev Neurosci 10:659-669.

Badre D, Wagner AD (2004) Selection, integration, and conflict monitoring; assessing the nature and generality of prefrontal cognitive control mechanisms. Neuron 41:473-487.

Barbas H (1995) Anatomic basis of cognitive-emotional interactions in the primate prefrontal cortex. Neurosci Biobehav Rev 19:499-510.

Barbas H, Mesulam MM (1985) Cortical afferent input to the principalis region of the rhesus monkey. Neuroscience 15:619-637.

Barbas H, Pandya DN (1989) Architecture and intrinsic connections of the prefrontal cortex in the rhesus monkey. J Comp Neurol 286:353-375.

Barbas H, Rempel-Clower N (1997) Cortical structure predicts the pattern of corticocortical connections. Cereb Cortex 7:635-646.

Barbas H, Zikopoulos B (2007) The prefrontal cortex and flexible behavior. Neuroscientist 13:532-545.

Barbas H, Ghashghaei H, Dombrowski SM, Rempel-Clower NL (1999) Medial prefrontal cortices are unified by common connections with superior temporal cortices and distinguished by input from memory-related areas in the rhesus monkey. J Comp Neurol 410:343-367.

Barbas H, Ghashghaei H, Rempel-Clower N, Xiao D (2002) Anatomic basis of functional specialization in prefrontal cortices in primates. In: Hand- book of neuropsychology, Vol 7: the frontal lobes (Grafman J, ed), pp 1-27. Amsterdam: Elsevier Science.

Beasley CL, Zhang ZJ, Patten I, Reynolds GP (2002) Selective deficits in prefrontal cortical GABAergic neurons in schizophrenia defined by the presence of calcium-binding proteins. Biol Psychiatry 52:708-715.

Benes FM (2000) Emerging principles of altered neural circuitry in schizophrenia. Brain Res Brain Res Rev 31:251-269.

Botvinick MM (2007) Conflict monitoring and decision making: reconciling two perspectives on anterior cingulate function. Cogn Affect Behav Neurosci 7:356-366.

Bourne JN, Harris KM (2008) Balancing structure and function at hippocampal dendritic spines. Annu Rev Neurosci 31:47-67.

Braver TS, Reynolds JR, Donaldson DI (2003) Neural mechanisms of transient and sustained cognitive control during task switching. Neuron 39:713-726.

Brewin CR, Smart L (2005) Working memory capacity and suppression of intrusive thoughts. J Behav Ther Exp Psychiatry 36:61-68.

Brown JW, Braver TS (2008) A computational model of risk, conflict, and individual difference effects in the anterior cingulate cortex. Brain Res 1202:99-108

Burgess PW, Veitch E, de Lacy Costello A, Shallice T (2000) The cognitive and neuroanatomical correlates of multitasking. Neuropsychologia $38: 848-863$.

Burgess PW, Gilbert SJ, Dumontheil I (2007) Function and localization within rostral prefrontal cortex (area 10). Philos Trans R Soc Lond B Biol Sci 362:887-899.

Bush G, Luu P, Posner MI (2000) Cognitive and emotional influences in anterior cingulate cortex. Trends Cogn Sci 4:215-222.

Callaway EM (1998) Local circuits in primary visual cortex of the macaque monkey. Annu Rev Neurosci 21:47-74.

Carter CS, Botvinick MM, Cohen JD (1999) The contribution of the anterior cingulate cortex to executive processes in cognition. Rev Neurosci 10:49-57.

Chen A, Xu P, Wang Q, Luo Y, Yuan J, Yao D, Li H (2008) The timing of cognitive control in partially incongruent categorization. Hum Brain Mapp 29:1028-1039.

Cohen JD, Braver TS, O'Reilly RC (1996) A computational approach to prefrontal cortex, cognitive control and schizophrenia: recent developments and current challenges. Philos Trans R Soc Lond B Biol Sci 351:1515-1527.

Condé F, Lund JS, Jacobowitz DM, Baimbridge KG, Lewis DA (1994) Local circuit neurons immunoreactive for calretinin, calbindin D-28k or parvalbumin in monkey prefrontal cortex: distribution and morphology. J Comp Neurol 341:95-116.

Constantinidis C, Procyk E (2004) The primate working memory networks. Cogn Affect Behav Neurosci 4:444-465.

Constantinidis C, Franowicz MN, Goldman-Rakic PS (2001) Coding specificity in cortical microcircuits: a multiple-electrode analysis of primate prefrontal cortex. J Neurosci 21:3646-3655.

Conway AR, Cowan N, Bunting MF (2001) The cocktail party phenomenon revisited: the importance of working memory capacity. Psychon Bull Rev 8:331-335.

Curtis CE, D'Esposito M (2004) The effects of prefrontal lesions on working memory performance and theory. Cogn Affect Behav Neurosci 4:528-539.

DeFelipe J (1997) Types of neurons, synaptic connections and chemical characteristics of cells immunoreactive for calbindin-D28K, parvalbumin and calretinin in the neocortex. J Chem Neuroanat 14:1-19.

DeFelipe J, Hendry SH, Jones EG (1989a) Synapses of double bouquet cells in monkey cerebral cortex visualized by calbindin immunoreactivity. Brain Res 503:49-54.

DeFelipe J, Hendry SH, Jones EG (1989b) Visualization of chandelier cell axons by parvalbumin immunoreactivity in monkey cerebral cortex. Proc Natl Acad Sci U S A 86:2093-2097.

del Río MR, DeFelipe J (1997) Synaptic connections of calretininimmunoreactive neurons in the human neocortex. J Neurosci 17:5143-5154.

Denham SL, Winkler I (2006) The role of predictive models in the formation of auditory streams. J Physiol Paris 100:154-170.

De Pisapia N, Slomski JA, Braver TS (2007) Functional specializations in lateral prefrontal cortex associated with the integration and segregation of information in working memory. Cereb Cortex 17:993-1006. 
Devinsky O, Morrell MJ, Vogt BA (1995) Contributions of anterior cingulate cortex to behaviour. Brain 118:279-306.

Dombrowski SM, Hilgetag CC, Barbas H (2001) Quantitative architecture distinguishes prefrontal cortical systems in the rhesus monkey. Cereb Cortex 11:975-988.

Douglas RJ, Martin KA (2004) Neuronal circuits of the neocortex. Annu Rev Neurosci 27:419-451.

Dreher JC, Koechlin E, Tierney M, Grafman J (2008) Damage to the frontopolar cortex is associated with impaired multitasking. PLoS One 3:e3227.

Eisenberg DP, Berman KF (2010) Executive function, neural circuitry, and genetic mechanisms in schizophrenia. Neuropsychopharmacology 35:258-277.

Emeric EE, Brown JW, Leslie M, Pouget P, Stuphorn V, Schall JD (2008) Performance monitoring local field potentials in the medial frontal cortex of primates: anterior cingulate cortex. J Neurophysiol 99:759-772.

Feldman ML, Peters A (1978) The forms of non-pyramidal neurons in the visual cortex of the rat. J Comp Neurol 179:761-793.

Felleman DJ, Van Essen DC (1991) Distributed hierarchical processing in the primate cerebral cortex. Cereb Cortex 1:1-47.

Fiala JC (2005) Reconstruct: a free editor for serial section microscopy. J Microsc 218:52-61.

Fiala JC, Harris KM (1999) Dendrite structure. In: Dendrites (Stuart G, Spruston N, Häusser M, eds), pp 1-34. Oxford: Oxford UP.

Fiala JC, Harris KM (2001a) Cylindrical diameters method for calibrating section thickness in serial electron microscopy. J Microsc 202:468-472.

Fiala JC, Harris KM (2001b) Extending unbiased stereology of brain ultrastructure to three-dimensional volumes. J Am Med Inform Assoc 8:1-16.

Fletcher P, McKenna PJ, Friston KJ, Frith CD, Dolan RJ (1999) Abnormal cingulate modulation of fronto-temporal connectivity in schizophrenia. Neuroimage 9:337-342.

Fornito A, Yücel M, Dean B, Wood SJ, Pantelis C (2009) Anatomical abnormalities of the anterior cingulate cortex in schizophrenia: bridging the gap between neuroimaging and neuropathology. Schizophr Bull 35:973-993.

Frith CD, Friston KJ, Herold S, Silbersweig D, Fletcher P, Cahill C, Dolan RJ, Frackowiak RS, Liddle PF (1995) Regional brain activity in chronic schizophrenic patients during the performance of a verbal fluency task. Br J Psychiatry 167:343-349.

Funahashi S (2006) Prefrontal cortex and working memory processes. Neuroscience 139:251-261.

Fuster JM (1973) Unit activity in prefrontal cortex during delayed-response performance: neuronal correlates of transient memory. J Neurophysiol 36:61-78.

Fuster JM (2001) The prefrontal cortex-an update: time is of the essence. Neuron 30:319-333.

Gabbott PL, Bacon SJ (1996) Local circuit neurons in the medial prefrontal cortex (areas 24a-c, 25 and 32) in the monkey: II. Quantitative areal and laminar distributions. J Comp Neurol 364:609-636.

Gehring WJ, Knight RT (2000) Prefrontal-cingulate interactions in action monitoring. Nat Neurosci 3:516-520.

Germuska M, Saha S, Fiala J, Barbas H (2006) Synaptic distinction of laminar specific prefrontal-temporal pathways in primates. Cereb Cortex 16:865-875.

Goldman-Rakic PS (1995) Cellular basis of working memory. Neuron 14:477-485.

Gonchar Y, Burkhalter A (2003) Distinct GABAergic targets of feedforward and feedback connections between lower and higher areas of rat visual cortex. J Neurosci 23:10904-10912.

González-Burgos G, Barrionuevo G, Lewis DA (2000) Horizontal synaptic connections in monkey prefrontal cortex: an in vitro electrophysiological study. Cereb Cortex 10:82-92.

Gundersen HJ, Bagger P, Bendtsen TF, Evans SM, Korbo L, Marcussen N, Møller A, Nielsen K, Nyengaard JR, Pakkenberg B, Sorensen FB, Vesterby A, West MJ (1988) The new stereological tools: disector, fractionator, nucleator and point sample intercepts and their use in pathological research and diagnosis. APMIS 96:857-881.

Hackett TA, Stepniewska I, Kaas JH (1999) Prefrontal connections of the parabelt auditory cortex in macaque monkeys. Brain Res 817:45-58.

Honey GD, Fletcher PC (2006) Investigating principles of human brain function underlying working memory: what insights from schizophrenia? Neuroscience 139:59-71.

Howard CV, Reed MG (1998) Unbiased stereology, three-dimensional measurement in microscopy. Oxford: BIOS Scientific Publishers.
Ito S, Stuphorn V, Brown JW, Schall JD (2003) Performance monitoring by the anterior cingulate cortex during saccade countermanding. Science 302:120-122.

Jäskeläinen IP, Ahveninen J, Belliveau JW, Raij T, Sams M (2007) Shortterm plasticity in auditory cognition. Trends Neurosci 30:653-661.

Johnston K, Levin HM, Koval MJ, Everling S (2007) Top-down controlsignal dynamics in anterior cingulate and prefrontal cortex neurons following task switching. Neuron 53:453-462.

Kawaguchi Y, Kubota Y (1997) GABAergic cell subtypes and their synaptic connections in rat frontal cortex. Cereb Cortex 7:476-486.

Kawaguchi Y, Karube F, Kubota Y (2006) Dendritic branch typing and spine expression patterns in cortical nonpyramidal cells. Cereb Cortex 16:696-711.

Kerns JG, Cohen JD, MacDonald AW 3rd, Johnson MK, Stenger VA, Aizenstein H, Carter CS (2005) Decreased conflict- and error-related activity in the anterior cingulate cortex in subjects with schizophrenia. Am J Psychiatry 162:1833-1839.

Koechlin E, Hyafil A (2007) Anterior prefrontal function and the limits of human decision-making. Science 318:594-598.

Koechlin E, Basso G, Pietrini P, Panzer S, Grafman J (1999) The role of the anterior prefrontal cortex in human cognition. Nature 399:148-151.

Koechlin E, Corrado G, Pietrini P, Grafman J (2000) Dissociating the role of the medial and lateral anterior prefrontal cortex in human planning. Proc Natl Acad Sci U S A 97:7651-7656.

Koechlin E, Ody C, Kouneiher F (2003) The architecture of cognitive control in the human prefrontal cortex. Science 302:1181-1185.

Larkman AU (1991) Dendritic morphology of pyramidal neurones of the visual cortex of the rat: III. Spine distributions. J Comp Neurol 306:332-343.

Lee D, Rushworth MF, Walton ME, Watanabe M, Sakagami M (2007) Functional specialization of the primate frontal cortex during decision making. J Neurosci 27:8170-8173.

Leicht G, Kirsch V, Giegling I, Karch S, Hantschk I, Möller HJ, Pogarell O, Hegerl U, Rujescu D, Mulert C (2010) Reduced early auditory evoked gamma-band response in patients with schizophrenia. Biol Psychiatry 67:224-231.

Levy R, Goldman-Rakic PS (2000) Segregation of working memory functions within the dorsolateral prefrontal cortex. Exp Brain Res 133:23-32.

Luebke J, Barbas H, Peters A (2010) Effects of normal aging on prefrontal area 46 in the rhesus monkey. Brain Res Rev 62:212-232.

Lynch JC, Tian JR (2006) Cortico-cortical networks and cortico-subcortical loops for the higher control of eye movements. Prog Brain Res 151:461-501.

MacDonald AW 3rd, Cohen JD, Stenger VA, Carter CS (2000) Dissociating the role of the dorsolateral prefrontal and anterior cingulate cortex in cognitive control. Science 288:1835-1838.

Matsumoto K, Tanaka K (2004) The role of the medial prefrontal cortex in achieving goals. Curr Opin Neurobiol 14:178-185.

McGuire PK, Silbersweig DA, Wright I, Murray RM, David AS, Frackowiak RS, Frith CD (1995) Abnormal monitoring of inner speech: a physiological basis for auditory hallucinations. Lancet 346:596-600.

McGuire PK, Silbersweig DA, Wright I, Murray RM, Frackowiak RS, Frith CD (1996) The neural correlates of inner speech and auditory verbal imagery in schizophrenia: relationship to auditory verbal hallucinations. Br J Psychiatry 169:148-159.

Medalla M, Barbas H (2006) Diversity of laminar connections linking periarcuate and lateral intraparietal areas depends on cortical structure. Eur J Neurosci 23:161-179.

Medalla M, Barbas H (2009) Synapses with inhibitory neurons differentiate anterior cingulate from dorsolateral prefrontal pathways associated with cognitive control. Neuron 61:609-620.

Medalla M, Lera P, Feinberg M, Barbas H (2007) Specificity in inhibitory systems associated with prefrontal pathways to temporal cortex in primates. Cereb Cortex 17 [Suppl 1]:i136-i150.

Melchitzky DS, Sesack SR, Pucak ML, Lewis DA (1998) Synaptic targets of pyramidal neurons providing intrinsic horizontal connections in monkey prefrontal cortex. J Comp Neurol 390:211-224.

Melchitzky DS, González-Burgos G, Barrionuevo G, Lewis DA (2001) Synaptic targets of the intrinsic axon collaterals of supragranular pyramidal neurons in monkey prefrontal cortex. J Comp Neurol 430:209-221.

Micheyl C, Carlyon RP, Gutschalk A, Melcher JR, Oxenham AJ, Rauschecker 
JP, Tian B, Courtenay Wilson E (2007) The role of auditory cortex in the formation of auditory streams. Hear Res 229:116-131.

Miller EK, Cohen JD (2001) An integrative theory of prefrontal cortex function. Annu Rev Neurosci 24:167-202.

Mitchell JP, Heatherton TF, Kelley WM, Wyland CL, Wegner DM, Neil Macrae C (2007) Separating sustained from transient aspects of cognitive control during thought suppression. Psychol Sci 18:292-297.

Moore CT, Wilson CG, Mayer CA, Acquah SS, Massari VJ, Haxhiu MA (2004) A GABAergic inhibitory microcircuit controlling cholinergic outflow to the airways. J Appl Physiol 96:260-270.

Mulert C, Leicht G, Pogarell O, Mergl R, Karch S, Juckel G, Möller HJ, Hegerl U (2007) Auditory cortex and anterior cingulate cortex sources of the early evoked gamma-band response: relationship to task difficulty and mental effort. Neuropsychologia 45:2294-2306.

Mulert C, Seifert C, Leicht G, Kirsch V, Ertl M, Karch S, Moosmann M, Lutz J, Möller HJ, Hegerl U, Pogarell O, Jäger L (2008) Single-trial coupling of EEG and fMRI reveals the involvement of early anterior cingulate cortex activation in effortful decision making. Neuroimage 42:158-168.

Müller NG, Knight RT (2006) The functional neuroanatomy of working memory: contributions of human brain lesion studies. Neuroscience 139:51-58.

Müller-Preuss P, Ploog D (1981) Inhibition of auditory cortical neurons during phonation. Brain Res 215:61-76.

Müller-Preuss P, Newman JD, Jürgens U (1980) Anatomical and physiological evidence for a relationship between the "cingular" vocalization area and the auditory cortex in the squirrel monkey. Brain Res 202:307-315.

Murthy VN, Sejnowski TJ, Stevens CF (1997) Heterogeneous release properties of visualized individual hippocampal synapses. Neuron 18:599-612.

Murthy VN, Schikorski T, Stevens CF, Zhu Y (2001) Inactivity produces increases in neurotransmitter release and synapse size. Neuron 32:673-682.

Ng CW, Noblejas MI, Rodefer JS, Smith CB, Poremba A (2007) Double dissociation of attentional resources: prefrontal versus cingulate cortices. J Neurosci 27:12123-12131.

Niki H, Watanabe M (1976) Prefrontal unit activity and delayed response: relation to cue location versus direction of response. Brain Res 105:79-88.

Nimchinsky EA, Sabatini BL, Svoboda K (2002) Structure and function of dendritic spines. Annu Rev Physiol 64:313-353.

Paus T (2001) Primate anterior cingulate cortex: where motor control, drive and cognition interface. Nat Rev Neurosci 2:417-424.

Pessoa L (2008) On the relationship between emotion and cognition. Nat Rev Neurosci 9:148-158.

Peters A, Sethares C (1997) The organization of double bouquet cells in monkey striate cortex. J Neurocytol 26:779-797.

Peters A, Palay SL, Webster HD (1991) The fine structure of the nervous system. Neurons and their supporting cells. New York: Oxford UP.

Petrides M (2005) Lateral prefrontal cortex: architectonic and functional organization. Philos Trans R Soc Lond B Biol Sci 360:781-795.

Petrides M, Pandya DN (1988) Association fiber pathways to the frontal cortex from the superior temporal region in the rhesus monkey. J Comp Neurol 273:52-66.

Pinto A, Jankowski M, Sesack SR (2003) Projections from the paraventricular nucleus of the thalamus to the rat prefrontal cortex and nucleus accumbens shell: ultrastructural characteristics and spatial relationships with dopamine afferents. J Comp Neurol 459:142-155.

Poremba A, Saunders RC, Crane AM, Cook M, Sokoloff L, Mishkin M (2003) Functional mapping of the primate auditory system. Science 299:568-572.

Poremba A, Malloy M, Saunders RC, Carson RE, Herscovitch P, Mishkin M (2004) Species-specific calls evoke asymmetric activity in the monkey's temporal poles. Nature 427:448-451.

Rauschecker JP, Tian B, Pons T, Mishkin M (1997) Serial and parallel processing in rhesus monkey auditory cortex. J Comp Neurol 382:89-103.

Reiner A, Veenman CL, Medina L, Jiao Y, Del Mar N, Honig MG (2000)
Pathway tracing using biotinylated dextran amines. J Neurosci Methods 103:23-37.

Romanski LM, Bates JF, Goldman-Rakic PS (1999) Auditory belt and parabelt projections to the prefrontal cortex in the rhesus monkey. J Comp Neurol 403:141-157.

Rosene DL, Roy NJ, Davis BJ (1986) A cryoprotection method that facilitates cutting frozen sections of whole monkey brains from histological and histochemical processing without freezing artifact. J Histochem Cytochem 34:1301-1315.

Rushworth MF, Buckley MJ, Behrens TE, Walton ME, Bannerman DM (2007) Functional organization of the medial frontal cortex. Curr Opin Neurobiol 17:220-227.

Schall JD, Boucher L (2007) Executive control of gaze by the frontal lobes. Cogn Affect Behav Neurosci 7:396-412.

Schmitz C, Hof PR (2005) Design-based stereology in neuroscience. Neuroscience 130:813-831.

Smith R, Keramatian K, Christoff K (2007) Localizing the rostrolateral prefrontal cortex at the individual level. Neuroimage 36:1387-1396.

Snitz BE, MacDonald A 3rd, Cohen JD, Cho RY, Becker T, Carter CS (2005) Lateral and medial hypofrontality in first-episode schizophrenia: functional activity in a medication-naive state and effects of short-term atypical antipsychotic treatment. Am J Psychiatry 162:2322-2329.

Somogyi P, Kisvárday ZF, Martin KA, Whitteridge D (1983) Synaptic connections of morphologically identified and physiologically characterized large basket cells in the striate cortex of cat. Neuroscience 10:261-294.

Somogyi P, Tamás G, Lujan R, Buhl EH (1998) Salient features of synaptic organisation in the cerebral cortex. Brain Res Brain Res Rev 26:113-135.

Tanji J, Hoshi E (2008) Role of the lateral prefrontal cortex in executive behavioral control. Physiol Rev 88:37-57.

Tong G, Jahr CE (1994) Multivesicular release from excitatory synapses of cultured hippocampal neurons. Neuron 12:51-59.

Tsujimoto S, Genovesio A, Wise SP (2010) Evaluating self-generated decisions in frontal pole cortex of monkeys. Nat Neurosci 13:120-126.

Veenman CL, Reiner A, Honig MG (1992) Biotinylated dextran amine as an anterograde tracer for single- and double-labeling studies. J Neurosci Methods 41:239-254.

Vogels TP, Abbott LF (2007) Gating deficits in model networks: a path to schizophrenia? Pharmacopsychiatry 40 [Suppl 1]:S73-S77.

Vogt BA, Barbas H (1988) Structure and connections of the cingulate vocalization region in the rhesus monkey. In: The physiological control of mammalian vocalization (Newman JD, ed), pp 203-225. New York: Plenum.

Volk DW, Lewis DA (2002) Impaired prefrontal inhibition in schizophrenia: relevance for cognitive dysfunction. Physiol Behav 77:501-505.

Wang XJ (1999) Synaptic basis of cortical persistent activity: the importance of NMDA receptors to working memory. J Neurosci 19:9587-9603.

Wang XJ, Tegnér J, Constantinidis C, Goldman-Rakic PS (2004) Division of labor among distinct subtypes of inhibitory neurons in a cortical microcircuit of working memory. Proc Natl Acad Sci U S A 101:1368-1373.

Wenzlaff RM, Wegner DM (2000) Thought suppression. Annu Rev Psychol 51:59-91.

White EL (1989) Cortical circuits. Synaptic organization of the cerebral cortex. Structure, function and theory. Boston: Birkhäuser.

Wyland CL, Kelley WM, Macrae CN, Gordon HL, Heatherton TF (2003) Neural correlates of thought suppression. Neuropsychologia 41:18631867.

Zaitsev AV, Gonzalez-Burgos G, Povysheva NV, Kröner S, Lewis DA, Krimer LS (2005) Localization of calcium-binding proteins in physiologically and morphologically characterized interneurons of monkey dorsolateral prefrontal cortex. Cereb Cortex 15:1178-1186.

Zikopoulos B, Barbas H (2006) Prefrontal projections to the thalamic reticular nucleus form a unique circuit for attentional mechanisms. J Neurosci 26:7348-7361.

Zikopoulos B, Barbas H (2007) Parallel driving and modulatory pathways link the prefrontal cortex and thalamus. PLoS One 2:e848. 